\title{
La investigación sobre comunicación en España en los últimos 25 años (1990-2014). Objetos de estudio y métodos aplicados en los trabajos publicados en revistas españolas especializadas
}

Communication research in Spain over the past 25 years (1990-2014). Objects of study and research methods in the papers published by Spanish peer-reviewed communication journals

\section{Manuel Martínez Nicolás \\ Universidad Rey Juan Carlos}

\section{ENRIC SAPERAS}

Universidad Rey Juan Carlos

\section{Ángel Carrasco-Campos}

Universidad de Valladolid

manuel.martinez.nicolas@urjc.es (ESPAÑA)

Recibido: 25.012018

Aceptado: 29.11 .2018

\section{RESUMEN}

Tras su institucionalización a comienzos de la década de los 70 con la creación de las primeras facultades de Ciencias de la Información, la investigación española sobre comunicación se consolida como ámbito disciplinar desde los años 90 con la multiplicación de la oferta de estos estudios en la universidad española, que propicia un crecimiento exponencial de la comunidad académica y de la producción científica en este campo. El ingente esfuerzo de metainves- 
tigación realizado en la última década, centrado especialmente en las revistas especializadas, y en menor medida en las tesis doctorales, está permitiendo reconstruir aspectos relevantes de la investigación comunicativa en España en este periodo, pero sin atender de manera suficiente a aquellos elementos que nos permitirían realizar un diagnóstico de la orientación epistemológica general que haya seguido la actividad científica en este ámbito. Este trabajo pretende contribuir en esa dirección mediante un análisis de contenido de una muestra de 1.098 artículos publicados entre 1990 y 2014 por seis revistas españolas especializadas de referencia, con el propósito de describir la evolución de los objetos de estudio y de los dispositivos metodológicos de la investigación española sobre comunicación en este periodo. Los resultados indican la progresiva diversificación de los objetos de estudio; la preeminencia de los trabajos sobre contenidos mediáticos, con una desatención creciente de la dimensión institucional del sistema comunicativo (empresas, profesionales, mercados, políticas públicas, etc.); el decaimiento de la investigación teórica; la mejora paulatina de la calidad metodológica de los trabajos empíricos publicados; y el predominio, cada vez más acusado, de la investigación cuantitativa, y especialmente de los análisis de contenido realizados sobre documentos de origen mediático (noticias, anuncios, series televisivas, etc.). Las tendencias observadas son discutidas apelando al impacto que hayan podido tener en la investigación española sobre comunicación los cambios experimentados por el sistema comunicativo (crecimiento del sector, advenimiento de la digitalización, etc.) y por el renovado contexto institucional (autonomización de las titulaciones de comunicación, implantación del programa Academia de acreditación del profesorado universitario) en el que ha venido desarrollándose la actividad científica en este ámbito disciplinar en el último cuarto de siglo.

\section{PALABRAS CLAVE}

Investigación sobre comunicación, España, revistas científicas, objetos de estudio, métodos de investigación.

\section{ABSTRACT}

After its institutionalisation during the early 1970s through the creation of the first faculties of Communication Sciences, Spanish communication research consolidates as a disciplinary field in the 1990s. During this period, the increasing number of universities degrees on communication studies led to an exponential growth of the academic community and, so, of the scientific production in the field. The enormous efforts of meta-research carried out in the last decade, specially focused on the study of peer-reviewed journals, and to lesser extent of $\mathrm{PhD}$ theses, have allowed the reconstruction of some relevant aspects of the current communication research in Spain. Nevertheless, these studies have not 
considered sufficiently those elements which would allow to identify the general epistemological orientation followed by the scientific activity in the field of communication. This paper intends to contribute to this research line. For this purpose, a content analysis has been applied to a sample of 1098 papers published between 1990 and 2014 by six major peer-reviewed communication journals, in order to observe the evolution of the objects of study and the methodological procedures in Spanish communication research during this period. The results show a progressive diversification of the objects of study, the pre-eminence of the studies on media content, a growing neglect of the institutional dimension of the media system (companies, professionals, markets, public policies, etc.), a decreasing interest on theoretical research, a gradual improvement of the methodological standards of empirical research, and a growing dominance of quantitative research, specially by means of content analysis applied to media documents (news, advertisements, television series, etc.). The observed trends are put for discussion considering the consequences that could have be generated on Spanish communication research by the changes of the media system (the growth of the communication sector, the advent of digitalization, etc.) and by the updated institutional context (the autonomy of university degrees in communication studies, the implementation of the Academia teaching acreditation programme) on which scientific activity has deveolped over the past 25 years.

\section{KEY WORDS}

Communication research, Spain, peer-reviewed journals, objects of study, research methods.

\section{INTRODUCCIÓN ${ }^{1}$}

La investigación sobre comunicación en España ha experimentado en el último cuarto de siglo una consolidación acelerada por el impulso de la radical transformación del marco institucional en el que comenzara a formarse el campo a comienzos de los años 70. El proceso de institucionalización académica iniciado en las postrimerías del franquismo con la creación de las primeras facultades de Ciencias de la Información se intensificará a partir de la década de los 90, cuando la multiplicación de los estudios de comunicación en las universidades españolas propicia un espectacular crecimiento y diversificación de la comunidad científica comprometida en este ámbito disciplinar (Jones, 1998; Moragas, 2005; Saperas, 2016). Esa dinámica expansiva se verá reforzada desde mediados de la primera década de los 2000 , en que empieza a dejarse sentir en el conjunto

1 Este trabajo forma parte del proyecto 25 años de investigación sobre Comunicación en España (1990-2015): producción científica, comunidad académica y contexto institucional, financiado por el Plan Estatal de I+D+i (CSO2013-40684-P). https://www.geac.es/incomes-25.es/ 
del sistema científico español el impacto de los nuevos requisitos para el acceso y promoción universitarias establecidas tras la creación de la ANECA en 2003 y la implantación del programa Academia de acreditación del profesorado en enero de 2008. El alto valor curricular atribuido a partir de entonces a la actividad investigadora, y en particular a aquella difundida en las revistas de mayor impacto, servirá de acicate para la producción científica en este campo, que se incrementa de forma exponencial en los últimos 10 o 15 años en cualquiera de los formatos de publicación, ya sean artículos en revistas (Fernández-Quijada y Masip, 2013; Piñeiro, 2016), libros y contribuciones a congresos (Soriano, 2017) o tesis doctorales (López Escobar y Martín Algarra, 2017).

La pujanza de la investigación comunicativa en España en esta última década ha venido acompañada de un creciente interés por someterla a escrutinio, convirtiendo eso que ahora denominamos metainvestigación en una de las más fecundas líneas de trabajo de diez años a esta parte. Centrada en las publicaciones en revistas especializadas, y en menor medida en tesis doctorales, esa metainvestigación parece, no obstante, excesivamente deudora de los enfoques bibliométricos que llevan a primar el análisis de los aspectos más objetivables de la producción científica (volumen de lo publicado, regímenes de autoría, universidades contribuyentes, redes de investigadores, etc.), descuidando, por lo general, la indagación sobre aquellas otras características (objetos de estudio, enfoques teórico-conceptuales, dispositivos metodológicos, técnicas empíricas utilizadas, etc.) que permiten una valoración más provechosa, desde el punto de vista epistemológico, del estado de la investigación en cualquier ámbito disciplinar. Por otra parte, los escasos trabajos disponibles que abordan estos aspectos suelen abarcar lapsos cortos, en ocasiones con muestras de no más de uno o dos años, que imposibilitan apreciar la evolución temporal de los parámetros estudiados, con una inclinación reciente, además, al análisis de áreas específicas, entre ellas la publicidad (Roca y Mensa, 2009; Martínez Pestaña, 2011; Marcos, Martínez Pestaña y Blasco, 2011; Martínez Pastor y García López, 2013; Baladrón, Correyero y Manchado, 2014; Baladrón, Manchado y Correyero, 2017), las relaciones públicas (Arceo, 2006; Castillo y Xifra, 2006; Míguez, Baamonde y Corbacho, 2014), el periodismo (Martínez Nicolás, 2006; Humanes, 2007; Goyanes y Peinado, 2014; Martínez Nicolás, Saperas y Carrasco-Campos, 2017), la radio (Repiso, Torres y Delgado, 2011a; Piñeiro, 2016), la televisión (Repiso, Torres y Delgado, 2011b; Gaitán, Lozano y Piñuel, 2016), la comunicación para el cambio social (Fernández Viso, 2012; Marí, 2017; Barranquero y Limón, 2017) o las teorías de la comunicación (De Miguel, 2007; García Jiménez, 2007; Rodrigo y García Jiménez, 2010; Silva y San Eugenio, 2014).

No abundan, por tanto, los estudios longitudinales que permitan constatar la orientación del conjunto de la investigación comunicativa española en un periodo temporal lo suficientemente amplio como para detectar los cambios que hayan podido afectarle, y atendiendo preferentemente a aquellos aspectos que permitan realizar un cierto diagnóstico, por impreciso que sea, sobre las opciones epistemológicas generales de la práctica investigadora en este campo. Este trabajo pretende contribuir en esa dirección mediante un análisis de contenido 
de una muestra de 1.098 artículos publicados entre 1990 y 2014 por autores adscritos a universidades y centros de investigación españoles en seis revistas especializadas en comunicación editadas en España, con el propósito de dar cuenta de la evolución de los objetos de estudio y de las metodologías utilizadas en la investigación comunicativa española en los últimos 25 años. La muestra analizada no es estadísticamente representativa de la totalidad de la producción científica española sobre comunicación en este cuarto de siglo, pero, dado el carácter referencial de las revistas seleccionadas, sí puede considerarse suficientemente indicativa de las tendencias generales de la investigación comunicativa en este periodo. Previamente, se revisan algunos de los hitos fundamentales en la historia de la investigación española sobre comunicación, incidiendo en aquellos factores que pudieran contribuir a situar en un contexto explicativo adecuado los resultados que se obtengan de aquel análisis.

\section{CONSTITUCIÓN DEL CAMPO Y EVOLUCIÓN DE LA INVESTIGACIÓN ESPAÑOLA SOBRE COMUNICACIÓN}

La investigación sobre comunicación no logra instituirse en España como ámbito de conocimiento arraigado en el campo científico hasta la década de los 70 del siglo pasado, acumulando un notable retraso con respecto a la mayoría de los países occidentales y de América Latina, que cuentan ya para entonces con trayectorias consolidadas. El férreo control ejercido por la dictadura franquista sobre las universidades y el sistema científico, quizá más estricto aún en el área de las ciencias sociales, y el magro desarrollo de un sector de la comunicación especialmente intervenido y vigilado para satisfacer las necesidades propagandísticas del régimen, impedirán hasta ese momento que se den las condiciones de dinamismo social, libertad académica y apertura intelectual indispensables para el despliegue de una actividad científica sostenida y sistemática en este ámbito (Moragas, 1981; Jones, 1998; Martínez Nicolás, 2006 y 2008; Lacasa, 2017). El impulso decisivo procedió, sin duda, de la creación en septiembre de 1971 de las primeras facultades de Ciencias de la Información en las universidades Complutense de Madrid y Autónoma de Barcelona, a las que se agregaría unos meses después, en abril de 1972, la de la Universidad de Navarra, regentada por el Opus Dei, y una década más tarde, en 1981, la de la Universidad del País Vasco, cerrando así la etapa inicial de la institucionalización académica de los estudios de comunicación en España.

Aquellas primeras facultades asumían la formación de profesionales sustituyendo a las Escuelas Oficiales precedentes de Periodismo, Radio y Televisión, Cinematografía, y Publicidad, que irán desapareciendo paulatinamente. Pero a pesar de esa impronta profesionalista heredada, esas nuevas facultades constituirán ya un marco institucional adecuado para que comience a fraguar en España una tradición científica de investigación sobre comunicación. De entrada, porque la relativa autonomía organizativa e intelectual de que disfrutaban permitía superar, o atemperar al menos, el rígido doctrinarismo de aquellas escuelas (Ido- 
yaga, 1990:119), cuya expresión probablemente más esperpéntica fuese la torpe pretensión de conformar una llamada doctrina española de la información para justificar la censura y el control informativo total (Moragas, 1981: 224-225). Pero, sobre todo, porque el rango universitario adquirido por los estudios de comunicación generó entonces una estructura de oportunidad para la profesionalización académica en este ámbito, cuyos mecanismos de acceso, consolidación y promoción exigían ya de una implicación insoslayable y continuada en la actividad científica (tesis doctorales, memorias para los concursos de provisión de plazas, etc.).

Las particulares circunstancias en que se produjo la emergencia del campo condicionarían el rumbo que tomará la investigación comunicativa en España en los siguientes 20 o 25 años. En primer lugar, su orientación preferente hacia el análisis del periodismo y la información periodística, descuidando el resto de los ámbitos mediáticos y profesionales relacionados con la comunicación pública (la publicidad, las relaciones públicas y la comunicación audiovisual, incluyendo el cine). No es casual que los primeros centros universitarios especializados adoptasen la denominación de facultades de "Ciencias de la Información", un apelativo que irán perdiendo en favor del más inclusivo de "Ciencias de la Comunicación", o simplemente "Comunicación", solo a partir de los años 90, cuando a las cuatro facultades fundacionales se vayan agregando otras de nueva creación (Martínez Nicolás, 2008). Y no es casual tampoco que a la hora de organizar el campo disciplinar en "áreas de conocimiento" para regular el acceso a los cuerpos docentes universitarios (Real Decreto 1888/1984) se decidiese singularizar la de "Periodismo" y agrupar lo restante en una segunda de "Comunicación Audiovisual y Publicidad" (sin mención alguna a las Relaciones Públicas, por cierto), algo indicativo de un imaginario académico que parecía otorgar una posición central y predominante al periodismo. Con todo, es probable que esa especie de decantación periodística inicial de la investigación comunicativa española respondiese también a las propias demandas de conocimiento de un periodo histórico, el de la transición democrática en España, en donde el reconocimiento de las libertades de prensa y expresión, la ruptura el monopolio informativo ejercido por la dictadura, las exigencias de profesionalización de un periodismo hasta entonces sometido a estricto control por parte del régimen, y la propia relevancia adquirida por la información periodística en un momento de enorme agitación social y política; es probable, decimos, que estas circunstancias orientasen a los investigadores de manera preferente hacia la reflexión y el análisis de la cambiante fenomenología del periodismo en esa época.

No obstante, la trayectoria de la investigación comunicativa española hasta bien entrada la década de los 90 estará fundamentalmente condicionada por las características y el perfil académico de la comunidad científica comprometida en el desarrollo del campo en esa etapa de emergencia ${ }^{2}$. El profesorado de las primeras facultades de Ciencias de la Información estuvo conformado por no

2 Para una explicación más detallada y matizada de esta cuestión, véase Martínez Nicolás, 2006: 146-151, у 2008: 21-23. 
menos de tres grupos o sectores de procedencia y adscripciones disciplinares diversas, que darán lugar a actitudes epistémicas claramente diferenciadas en relación con la orientación formativa que debían tomar aquellos nuevos centros universitarios y, sobre todo, con el sentido en que debía conducirse la investigación sobre comunicación. El cuadro docente inicial de estas facultades se nutrió, básicamente, de profesores y exalumnos de las antiguas Escuelas Oficiales; de licenciados y doctores formados preferentemente en el ámbito de las humanidades (derecho, filología, estudios literarios, historia, lingüística, filosofía, etc.); y de profesionales del sector de la comunicación (periodistas, publicitarios, técnicos de radio y televisión, etc.). Esta composición del profesorado generará, de entrada, una pugna soterrada -que se manifiesta claramente en los sucesivos planes de estudio de la licenciatura- entre practicistas y teoricistas, enfrentados por la definición del papel que correspondería a las recién creadas facultades: si dirigidas a una formación estrictamente instrumental que capacitase para el ejercicio profesional en las empresas, o si, por el contrario, debían ampliar ese horizonte meramente profesionalista para constituir un ámbito científico específicamente orientado al análisis de la comunicación, y en general de la cultura de masas $^{3}$. A su vez, en este sector teoricista podía advertirse una segunda línea de fractura que separaba a aquellos investigadores empeñados en fundamentar una comunicología autónoma, por lo general desvinculada de los enfoques heurísticos y los métodos empíricos de las restantes ciencias sociales, de quienes, con una formación académica de carácter humanístico, exploraban los fenómenos comunicativos desde la óptica de sus respectivas disciplinas (historia, derecho, filosofía, semiótica, etc.).

En cualquier caso, lo característico de esta fase inicial de la constitución del campo fue la práctica ausencia de efectivos procedentes de las ciencias sociales (sociología, economía, antropología, psicología, ciencia política, etc.), y eso probablemente por una combinación de factores. En primer lugar, porque, en el contexto del tímido aperturismo académico de finales del franquismo se encontraban ellas mismas inmersas en un proceso de consolidación institucional en la universidad española, con escasa capacidad, por tanto, para generar excedentes con los que nutrir a las nuevas facultades de Ciencias de la Información, algo que sí podían ofrecer, en cambio, unas humanidades tradicionalmente bien asentadas. Es posible también que el paupérrimo desarrollo del sector de la comunicación en la España del momento, drásticamente cercenado por la dictadura, lo convirtiese en un ámbito de escaso interés para los investigadores en ciencias sociales, y menos aún en una coyuntura histórica en que la profunda transformación social, política, económica y cultural de la sociedad española ofrecía a esas disciplinas fenómenos seguramente más sugestivos para emprender sobre ellos

3 La distinción propuesta por Borrat (1990) entre profesionalistas y comunicólogos en relación con la enseñanza y la investigación del periodismo da cuenta de esta fractura de la comunidad científica en el momento de su constitución, aunque utiliza la identificación de comunicólogos en un sentido más restringido que el que le hemos dado en otros trabajos (véase especialmente Martínez Nicolás, 2006: 147-148). 
programas de investigación atractivos (el consumo, las organizaciones políticas, los movimientos sociales, la modernización de las estructuras empresariales y económicas, las nuevas actitudes y comportamientos culturales, etc.).

Como quiera que sea, lo cierto es que la investigación comunicativa española echa a andar a comienzos de los 70 prácticamente ayuna de arraigo en las ciencias sociales, en sus dispositivos teórico-conceptuales y en sus herramientas y prácticas metodológicas, quedando convertida durante dos décadas largas, hasta los años 90, en un campo disciplinar con vocación eminentemente humanística, alcanzando, no obstante, resultados que no pueden menospreciarse. Debido a esa desvinculación con respecto a las ciencias sociales, la investigación española no estará en condiciones de aprovechar la profunda renovación propiciada en los años 60 por la crisis de la mass communication research y la irrupción, ya en los 70, de las recuperadas tradiciones interpretativistas (socio-fenomenología, etnometodología, interaccionismo simbólico, etc.) y de las propuestas actualizadas surgidas del positivismo (agenda-seting, espiral del silencio, knowledge gap, teoría del cultivo, usos y gratificaciones, etc.). Esa agitación en el campo ${ }^{4}$ no pasará desapercibida, desde luego. Pero su impacto durante los años 80 no irá mucho más allá de la mera recepción de esas nuevas aproximaciones -por lo general en forma de manuales para la docencia de las teorías de la comunicación-, con escasa capacidad para agitar una investigación en la que se manifiestan entonces claramente las deficiencias formativas en la teoría social, en un sentido amplio, y, sobre todo, en las metodologías empíricas necesarias para contribuir con aportaciones originales y homologadas al estándar científico requerido en los circuitos internacionales de producción y difusión del conocimiento (congresos, revistas científicas, equipos de investigación transnacionales, etc.).

El proceso inicial de institucionalización académica que culmina a principios de los 80 con las primeras facultades de Ciencias de la Información se verá ampliamente reforzado desde los 90 por el incremento espectacular de la oferta de estudios universitarios sobre comunicación en España, probablemente espoleado por la demanda de profesionales para un sector en plena expansión tras la liberalización del sistema televisivo a finales de los 80, con un impacto indudable en los mercados publicitario y de la producción audiovisual. A esa inercia expansiva se agregará desde comienzos de los 2000 el advenimiento de internet y la revolución digital, que vuelve a situar a estos centros y las titulaciones que imparten en una posición de crecimiento inmejorable, sostenido hasta hoy mismo. La explosión de los estudios de comunicación en los últimos 25 años tendrá consecuencias evidentes para la investigación en este campo, al multiplicarse exponencialmente el volumen de la comunidad científica implicada en su desarrollo. A mediados de los 80, las cuatro facultades existentes reunían a unos 5.000 estudiantes y alrededor de 500 profesores, pero transcurridos no

${ }^{4}$ La renovación de la investigación comunicativa en la década de los 70 fue ampliamente revisada por Journal of Communication, revista de referencia editada por la International Communication Association (ICA), en un monográfico publicado en 1983 (volumen 33, número 3) con el expresivo título de Ferment in the field (agitación, pero también savia nueva, en el campo). 
más de diez años, mediada la década de los 90, esos parámetros se habían cuadruplicado, siendo para entonces 20 las universidades con titulaciones de comunicación, con 20.000 alumnos matriculados y en torno a 2.000 docentes (Jones, 1998). Esta expansión no hará sino intensificarse en lo sucesivo. A mediados de la primera década de los 2000, 44 universidades tienen implantados estos estudios, con un número de profesores que ronda los 3.000 efectivos (ANECA, 2005; Moragas, 2005; Abuín, 2010). Y los datos actualizados más fiables indican que para 2017 serían ya 67 las universidades españolas con programas de grado en comunicación (Civil, 2018), que seguirían alrededor de 45.000 estudiantes a cargo de un cuerpo docente, y potencialmente investigador, integrado por unos 4.500 profesores (Saperas, 2016).

El crecimiento inusitado de los estudios de comunicación en España en este último cuarto de siglo acaba generando una segunda estructura de oportunidad para la profesionalización académica en este ámbito, cuyo impacto puede fácilmente rastrearse observando la evolución de las tesis doctorales defendidas en las facultades de Comunicación. Los datos de López Escobar y Marín Algarra (2017: 97-98) indican que entre 1979, fecha de la primera registrada, y 1989, los ejercicios doctorales defendidos fueron 250 , y se duplicaron holgadamente en la década posterior (569 entre 1990 y 1998). En la etapa más reciente, entre 2007 y 2013, vuelven prácticamente a duplicarse hasta alcanzar las 948, con una media anual de 135 nuevos doctores en cada uno de esos siete años. Aunque los bloques temporales que ofrecen los autores no sean homogéneos, e incluyan, además, los trabajos realizados por doctorandos extranjeros -habitualmente estudiantes latinoamericanos-, la progresión geométrica que revelan estas cifras da idea clara del modo en que aquella estructura de oportunidad abierta desde comienzos de los 90 ha propiciado el crecimiento de la comunidad científica en los últimos 20 o 25 años.

Si estas condiciones favorecen ya de por sí una producción académica que podría calificarse de inflacionaria, los requisitos impuestos para el acceso y promoción universitarias desde la creación de la ANECA en 2003 y la implantación a comienzos de 2008 del programa Academia de acreditación del profesorado, que otorga un valor central a la actividad investigadora, no harán sino dotar de un contenido bien explícito a aquella máxima competitiva del publish or perish. Este nuevo marco institucional, que afecta al conjunto del sistema científico español, propiciará en la última década un incremento notabilísimo de la producción científica sobre comunicación, y especialmente la de aquella publicada en las revistas especializadas de mayor impacto y rendimiento curricular (Fernández Quijada y Masip, 2013; Piñeiro, 2016), impulsando además la presencia regular de la investigación comunicativa española en el ámbito internacional (Masip, 2011; De Filippo, 2013; Escribà y Cortiñas, 2013; Fernández Quijada, Masip y Bergillos, 2013; Martínez Nicolás, 2014). Como quiera que sea, y más allá de estos indicadores sobre el incremento de la productividad científica en el campo, lo cierto es que el impacto que haya podido tener ese "efecto ANECA" (Soriano, 2008) en la orientación y las características de la investigación comunicativa solo ha comenzado a ser atendido muy recientemente (Martínez Nicolás 
y Saperas, 2016; Lacasa, 2017; Goyanes, 2017; Martínez Nicolás, Saperas y Carrasco-Campos, 2017; Soriano, 2017).

Como decíamos, la metainvestigación comunicativa española, justamente revitalizada coincidiendo con esta coyuntura de presión institucional sobre el sistema científico, no ha sido pródiga en el análisis y discusión de aquellos aspectos heurísticos (objetos de estudio, marcos teóricos, métodos y técnicas empíricas, etc.) que permitirían una adecuada crítica epistemológica de la investigación realizada en este ámbito disciplinar. Con todo, y al margen de las indagaciones en áreas específicas (publicidad, periodismo, relaciones públicas, etc.), disponemos de algunos trabajos que aportan datos sobre el conjunto de la investigación. Martínez Nicolás y Saperas (2011) analizaron los artículos de cuatro revistas editadas en España en una muestra correspondiente a la década 1998-2007 (N = 235), y observaron que prácticamente la mitad de ellos se ocupaban de aspectos relacionados con el periodismo o la información periodística, muy por encima de los dedicados a la comunicación audiovisual (17\%), la publicidad y el márketing $(7,6 \%)$ o las relaciones públicas y la comunicación corporativa $(5,1 \%)$. En la actualización de ese análisis (Martínez Nicolás y Saperas, 2016) para el periodo 2008-2014 ( $\mathrm{N}=529)$, se obtuvieron resultados similares, si bien la investigación periodística había decaído ligeramente (algo más del 45\% de los textos) y se había incrementado el interés por la comunicación audiovisual $(23,3 \%)$ y las relaciones públicas (casi el 9\%). Castillo y Carretón (2010) estudiaron los artículos publicados en diez revistas españolas solo en $2008(\mathrm{~N}=256)$, y observaron que el periodismo era la "temática" predominante $(22,3 \%)$, a distancia de la televisión $(13,7 \%)$, la publicidad $(9 \%)$ o las relaciones públicas $(7,4 \%)$. Esa misma decantación periodística se advierte también en los resultados obtenidos por Martínez Nicolás (2014) sobre los artículos en revistas internacionales incluidas en JCR y Scopus entre 2003 y 2012 ( $\mathrm{N}=196)$, en donde alrededor del $25 \%$ abordaba el periodismo, y algo más del $16 \%$ las relaciones públicas y la comunicación corporativa, con porcentajes menores en los casos de la comunicación audiovisual $(11,7 \%)$ y la publicidad y márketing $(11,2 \%)$, y una muy significativa presencia de trabajos sobre internet y el entorno digital (el 18,5\% de los publicados en esas revistas internacionales).

Más escasa es la evidencia sobre los dispositivos metodológicos empleados en la investigación española sobre comunicación, pero los resultados obtenidos hasta el momento indican que la producción científica en este campo, al menos la difundida en revistas especializadas, habría incurrido en serias deficiencias. Martínez Nicolás y Saperas (2011) constataron en su análisis de la década 19982007 que, dependiendo de año considerado, entre el 30\% y el 45\% de los trabajos empíricos $(\mathrm{N}=179)$ había sido realizado sin recurrir a técnicas sistemáticas y estandarizadas para acceder a los datos en que se apoyaban. Una situación parecida observaron López Rabadán y Vicente (2011) en cuatro revistas españolas entre 2000 y 2009 ( $(\mathrm{N}=80)$, en las que el 43,8\% de los artículos empíricos no contenía referencia alguna a los procedimientos metodológicos seguidos, y solo en el 23,8\% se incluía "un capítulo detallado sobre metodología". Solo para el año 2008, aunque ampliando la muestra a diez revistas $(\mathrm{N}=256)$, Castillo y 
Carretón (2010: 313) anotan que "sorprende que en un 23,9\% de los artículos no exista método alguno".

Esta situación de evidente desidia metodológica se habría ido modificando en la última década. Castillo, Almansa y Álvarez Nobell (2013) analizaron los métodos y técnicas utilizados en los artículos publicados en cuatro años del periodo 2000-2012 por cinco revistas especializadas editadas en España $(\mathrm{N}=$ 705), y constatan que el porcentaje de los "artículos sin ningún tipo de referencia textual de metodología" pasa del 26,1\% para el conjunto de la muestra en 2000 al $15,0 \%$ en 2012. En un sentido coincidente, Martínez Nicolás y Saperas (2016) observaron que ya solo alrededor del $20 \%$ de la investigación empírica publicada por cinco revistas españolas entre 2008 y $2014(\mathrm{~N}=460)$ presentaba este tipo de deficiencias, con tendencia a disminuir al final del periodo analizado (algo más del 10\% de los textos en 2014). Aunque escasos, los datos disponibles advierten, por tanto, de que la investigación comunicativa española no habría alcanzado sino hasta muy recientemente el nivel de rigor metodológico exigible a la producción del conocimiento científico en cualquier ámbito disciplinar.

\section{OBJETIVOS Y MÉTODO}

En este trabajo abordamos la evolución de la investigación española sobre comunicación en los últimos 25 años mediante un análisis de contenido de los artículos publicados entre 1990 y 2014 por autores adscritos a universidades y centros radicados en España en una muestra de revistas españolas especializadas, atendiendo específicamente a dos aspectos:

(a) Los objetos de estudio que atraen el interés de la comunidad científica, que se manifestarían en la elección para la investigación de determinados ámbitos mediáticos o profesionales relacionados con la comunicación (periodismo, comunicación audiovisual, publicidad, etc.), y de unos u otros aspectos o dimensiones del proceso comunicativo (emisores, contenidos, audiencias, efectos, etc.).

(b) La orientación metodológica de los trabajos publicados, para dar cuenta de los tipos de investigación (teórica, empírica o propiamente metodológica), y, específicamente en relación a aquella de carácter empírico, el enfoque metodológico adoptado (cuantitativo, cualitativo, mixto, etc.), las técnicas utilizadas (encuesta, análisis de contenido, grupos de discusión, etc.) y el tipo de fuente de datos (vivas o documentales) a partir de la que se genera la evidencia empírica en que se apoya este tipo de investigación.

La difundida en revistas especializadas no agota la producción científica generada en cualquier campo, y obviamente tampoco en el de la comunicación (Soriano, 2017). No obstante, la posición que ocupan las revistas en el sistema de difusión del conocimiento científico las convierte en una opción especialmen- 
te significativa para observar las tendencias epistemológicas generales en las que se mueve una disciplina. De entrada, porque al ser editadas con una alta periodicidad -semestral o trimestral, en la mayoría de los casos-acogen las líneas de trabajo más recientes y novedosas, constituyendo, por tanto, un indicador fiable de los intereses de conocimiento de una comunidad científica en un momento histórico dado, o de su evolución a lo largo del tiempo. Por otra parte, la publicación en revistas académicas está sometida a controles externos a los propios autores, pero arbitrados en el seno de la propia comunidad científica -la revisión por pares-, lo que debiera garantizar que los trabajos difundidos no obedecen más que al designio de ampliar el conocimiento disponible, y, sobre todo, que se valoran exclusivamente según criterios de rigor y validez científicos. Siendo estos protocolos probablemente más estrictos en las revistas que en otros dispositivos para la difusión científica -colecciones editoriales, congresos, etc.-, la calidad de los trabajos que publican puede ser indicativa del nivel de exigencia epistemológica (teórico-conceptual, metodológica, etc.) en que se desenvuelve la actividad investigadora en un ámbito disciplinar determinado.

\subsection{Diseño muestral}

Se seleccionaron seis revistas editadas en España y especializadas en investigación sobre comunicación: Anàlisi (Universidad Autónoma de Barcelona), Comunicación y Sociedad (Universidad de Navarra), Estudios sobre el Mensaje Periodístico (Universidad Complutense de Madrid), Zer (Universidad del País Vasco), Comunicar (Grupo Comunicar) y Revista Latina de Comunicación Social (Universidad de La Laguna), las cuatro primeras vinculadas a las facultades fundacionales del campo en España, y las dos últimas, representativas de la nueva hornada de centros y revistas surgida con la explosión de los estudios de comunicación en España desde comienzos de los 90. No obstante, la selección de estas cabeceras estuvo guiada por criterios relativos a la posición que ocupan en el ecosistema de las revistas sobre comunicación en España, atendiendo tanto a indicadores bibliométricos como a la valoración generada a partir del juicio experto. Cuatro de esas revistas (Comunicación y Sociedad, Zer, Estudios sobre el Mensaje Periodístico y Revista Latina de Comunicación Social, por este orden) ocupan las cuatro primeras posiciones en el índice de impacto acumulado de InRECS (Universidad de Granada) para el periodo 1994-20095. En ese índice, la revista Comunicar se sitúa en la décima posición, pero en el acumulado para el periodo 2000-2009 escala hasta la posición sexta, y para el periodo 2005-2009, se sitúa en la quinta ${ }^{6}$, siendo estos los últimos índices disponibles en In-RECS, y los más aproximados al lapso temporal cubierto por este trabajo. En el impacto acumulado correspondiente a 2005-2009 del índice RESH (Consejo Superior de

${ }^{5}$ Disponible en http://ec3.ugr.es/in-recs/acumulados/Comunicacion-5.htm,

${ }^{6}$ Disponibles, respectivamente, en http://ec3.ugr.es/in-recs/acumulados/Comunicacion10agnos-5.htm y http://ec3.ugr.es/in-recs/acumulados/Comunicacion-5agnos-5.htm 
Investigaciones Científicas ${ }^{7}$ ), también el último disponible, cinco de estas revistas ocupan las primeras posiciones (Revista Latina de Comunicación Social, Zer, Comunicación y Sociedad, Estudios sobre el Mensaje Periodístico y Comunicar). En la clasificación elaborada en 2009 por RESH utilizando como indicador el prestigio de las publicaciones a juicio de un panel de expertos, ocuparon las cinco primeras posiciones las revistas Comunicar, Zer, Comunicación y Sociedad, Revista Latina de Comunicación Social y Anàlisi. En algún momento de su trayectoria editorial, que coincide básicamente con el periodo analizado en este trabajo, todas las revistas seleccionadas han estado incluidas en las bases de datos internacionales más prestigiosas, entre ellas los Journal Citation Reports (JCR) y Scopus. Comunicación y Sociedad y Estudios sobre el Mensaje Periodístico fueron revistas JCR en las ediciones de 2010, 2011 y 2012, y Comunicar lo es ininterrumpidamente desde la de 2009, habiendo alcanzado el Q1 en 2015. Estas tres, junto con Revista Latina de Comunicación Social, han ido ingresando también en Scopus entre 2009 y 2012, y se han estabilizado en las ediciones más recientes en los Q1 y Q2. Los trabajos publicados por estas seis revistas deben tenerse, en consecuencia, por representativos de la investigación comunicativa española de mayor calidad e influencia en los diferentes momentos del periodo histórico aquí estudiado, dado el carácter referencial de las mismas para la comunidad científica de acuerdo con los indicadores bibliométricos y de prestigio disponibles.

Solo dos de las revistas seleccionadas han tenido continuidad en el periodo analizado (Anàlisi, que se edita desde 1980; y Comunicación y Sociedad, desde 1988), circunstancia que condicionó la construcción del corpus final de artículos analizados. Por otra parte, se valoró también el hecho de que cualquier revista precisa de un tiempo para afinar los protocolos de evaluación y aceptación de originales, y con ello la calidad de los trabajos que publica, por lo que se decidió ir incluyéndolas no desde su inicio, sino tras acreditar una cierta trayectoria. Teniendo en cuenta estos condicionantes y criterios, en el diseño muestral se tomó la década como unidad significativa y fueron incorporándose nuevas revistas en la transición entre las mismas. Así, en la etapa inicial (1990-1994) de los 25 años que abarca el estudio (1990-2014) solo se incluyeron artículos publicados por Anàlisi y Comunicación y Sociedad, agregándose Estudios sobre el Mensaje Periodístico y Zer al final de la primera década (desde 1998), y Comunicar y Revista Latina de Comunicación Social al final de la segunda (desde 2008). Posteriormente se procedió a la determinación de los años muestrales dividiendo el periodo 1990-2014 en cinco quinquenios y eligiendo de cada uno de ellos tres años, de acuerdo con un criterio cronológico sistemático por el que fueron seleccionados los años iniciales de cada uno de esos quinquenios (1990, 1995, 2000, 2005 y 2010) y los dos intermedios (1992, 1993, 1997, 1998, 2002, 2003, 2007, 2008, 2012 y 2014), criterio que se altera en último lustro solo para acercar en lo posible los resultados al momento presente. Aplicando este procedimiento, el

\footnotetext{
${ }^{7}$ Disponible en http://epuc.cchs.csic.es/resh/indicadores (Ciencias Sociales-Comunicación).
} 
diseño muestral final incluyó todos los trabajos publicados por aquellas revistas, progresivamente incorporadas, en 15 de los 25 años estudiados (el 60\% de esos años), conformando un corpus de 1.332 artículos de un total de 2.129 difundidos por estas revistas en el periodo que de cada una de ellas se cubre en este trabajo, operando, por tanto, con un margen de error del 2,2\% para un intervalo de confianza del 99\%. De aquellos 1.332 artículos, 1.098 (el 82,4\%) eran trabajos de autores adscritos a universidades y otros centros de investigación radicados en España, que constituyen el correlato empírico de lo que aquí se considera investigación española sobre comunicación.

\subsection{Criterios de codificación y fiabilidad}

La unidad sobre la que se recogieron los datos para el análisis de contenido fue el "artículo" -es decir, los informes de investigación identificados con un título-, y a cada uno de los 1.098 incluidos en el corpus final se le aplicó una ficha de codificación con seis variables relativas a los objetos de estudio o temas de interés para los investigadores y a la orientación metodológica de esos trabajos. Los datos sobre esas variables se obtuvieron de acuerdo con los siguientes criterios de codificación:

Objetos de estudio. Los objetos de estudio frecuentados por los investigadores indican los intereses de conocimiento de una comunidad científica en relación con el campo fenoménico en el que trabaja (en este caso, la comunicación). No obstante, la determinación empírica de aquellos objetos no es algo que pueda decidirse de manera inmediata, dado el carácter multidimensional de lo indicado por el término objeto de estudio, por lo que se decidió observar este aspecto mediante dos variables:

(a) El ámbito mediático o profesional vinculado a la comunicación cuyo estudio se aborda en los artículos analizados, estableciendo 12 categorías excluyentes que fueron recodificadas en seis para distinguir los trabajos dedicados al periodismo; la comunicación audiovisual (que incluye radio, televisión, cine, cómic, fotografía y cartel); la publicidad y el márketing; las relaciones públicas y la comunicación corporativa e institucional; internet y medios digitales (blogs, redes sociales, plataformas audiovisuales, etc.; es decir, excluyendo lo relativo a la digitalización vinculada a otros ámbitos -por ejemplo, el "periodismo digital" o "las webs corporativas"-, codificados en su categoría correspondiente); y otros, categoría residual que recogía aquellos artículos con temáticas genéricas (comunicación, comunicación mediática, etc.) o en los que se registraron finalmente pocos casos (comunicación interpersonal, propaganda y telecomunicaciones).

(b) El objeto de estudio específico en relación con cada uno de los ámbitos mediáticos o profesionales, con tal de identificar la dimensión o elemento del proceso comunicativo atendido en los trabajos analizados. Para la categoriza- 
ción de esta variable se adaptó la conocida segmentación propuesta por Lasswell (1948), distinguiendo los valores no excluyentes -en previsión de que un determinado artículo pudiera ocuparse de varias de estas dimensiones- de empresas e instituciones (incluyendo aquí lo referido a mercados y políticas de comunicación); profesionales; contenidos; tecnologías; audiencias y usuarios; y efectos e influencia, a las que se agregaron las de docencia e investigación. Esta variable permitía captar la diferencia, en cuanto al objeto de estudio específico, entre, por ejemplo, sendas investigaciones sobre "publicidad" que abordasen, una, la representación de la mujer en los anuncios de las revistas femeninas (codificada en la categoría de "contenidos"); otra, sobre los condicionantes deontológicos en el trabajo de los creativos publicitarios (codificada en la categoría de "profesionales"); una tercera, sobre los cambios en el mercado publicitario tras el advenimiento de la televisión privada en España (codificada en "empresas e instituciones"); y una cuarta, en fin, sobre las reacciones de los espectadores ante la publicidad de servicio público (codificada como "efectos e influencia"). Todos estos trabajos serían, efectivamente, investigaciones sobre "publicidad", pero enfocando cada una de ellos elementos distintos (emisores, contenidos, efectos, etc.) del proceso de la comunicación publicitaria, de manera que la obtención de este dato permite afinar la caracterización de los intereses de conocimiento de la comunidad científica en relación con la publicidad.

Orientación metodológica. Para este aspecto se observó el comportamiento empírico de cuatro variables:

(a) El tipo de investigación al que pudieran adscribirse los artículos analizados, distinguiendo las categorías excluyentes de investigación teórica (trabajos dedicados a exponer y discutir teorías, conceptos, revisiones del estado de la cuestión, etc.), metodológica (propuestas sobre métodos, técnicas o instrumentos y procedimientos de investigación) y empírica (análisis de cualquier faceta de la realidad fenoménica de la comunicación: funcionamiento de las empresas, regulaciones legales, procesos de producción, perfiles profesionales, discursos mediáticos, composición de las audiencias, influencia social de los medios, etc.).

(b) El enfoque metodológico adoptado en los estudios empíricos, para lo que se establecieron las categorías excluyentes de investigación cuantitativa, cualitativa, mixta (cuantitativa y cualitativa), con apoyo en fuentes documentales y empírica sin técnicas sistemáticas o estandarizadas. Las tres primeras categorías se codificaron atendiendo al tipo de técnicas utilizadas para la obtención de datos, según se tratase de aquellas propias de los métodos cuantitativo (encuesta, análisis de contenido, diseños experimentales, etc.), cualitativo (grupo de discusión, entrevistas en profundidad, análisis del discurso, etc.), o bien una combinación de ambas. En la categoría referida a "investigación con apoyo en fuentes documentales" se codificaron aquellos trabajos -erróneamente considerados en ocasiones como investigación cualitativa- que obtienen la evidencia empírica del análisis de materiales procedentes de archivos históricos, o bien de la amplia 
variedad de documentación generada por instituciones políticas, legislativas, judiciales, profesionales o empresariales (informes, dictámenes, reglamentos, directivas, leyes, programas electorales, sentencias, memorandos, códigos deontológicos, etc.), y que no eran "tratados" con ninguna de aquellas técnicas cuantitativas o cualitativas. Este tipo de investigación empírica es frecuente en algunas áreas específicas (por ejemplo, en la historia de la comunicación, o en los estudios sobre estructura y organización del sistema comunicativo, o sobre políticas públicas sectoriales). Por lo que hace a la "investigación sin técnicas sistemáticas o estandarizadas", se adscribieron a esta categoría aquellos trabajos que, abordando aspectos fenoménicos de la comunicación (contenidos mediáticos, rutinas profesionales, actividad de las audiencias, efectos de los medios, etc.) no apoyaban sus resultados en datos obtenidos mediante procedimientos estandarizados por la literatura metodológica (ya fuesen técnicas sistemáticas, $o$ protocolos para el manejo y análisis de fuentes documentales), siendo aportaciones más cercanas al comentario o la reflexión a partir de impresiones personales que al rigor exigible a la investigación científica. Los codificados en esta categoría fueron considerados, por tanto, trabajos metodológicamente deficientes, producto de una mala praxis investigadora.

(c) Las técnicas para la obtención de datos en los estudios empíricos con procedimientos sistemáticos o estandarizados, variable para la que se establecieron 11 categorías no excluyentes que incluían la práctica totalidad de las usuales en la investigación social (análisis de contenido, encuesta, grupos de discusión, observación etnográfica, análisis discursivo, investigación sobre fuentes documentales, diseños experimentales, métodos biográficos, investigación secundaria, técnica Delphi y entrevista en profundidad).

(d) Las fuentes de datos de la que se extrae la evidencia empírica-vinculadas, obviamente, al carácter de las técnicas utilizadas para el acceso a los datos-, a partir de una distinción básica entre fuentes vivas (personas), secundarias (datos disponibles, generalmente cuantitativos) y documentales, diferenciado en estas últimas entre documentos mediáticos (noticias, anuncios, etc.), institucionales (informes, reglamentos, sentencias, etc.), académicos (planes de estudio, artículos científicos, etc.) o del entorno digital no mediático (blogs, intervenciones en redes sociales, vídeos en plataformas de internet, etc.).

El corpus de 1.098 artículos finalmente constituido se distribuyó entre dos investigadores previamente entrenados mediante la aplicación de los criterios de codificación a un $10 \%$ de la muestra. Posteriormente se realizó una prueba de fiabilidad sobre otro $10 \%$ de ese corpus que, aun ofreciendo un nivel estadístico óptimo (con un valor medio para el conjunto de las variables de 0,71 en la pi de Scott), se decidió reforzar con una doble codificación independiente de todos los artículos por un tercer investigador, discutiendo caso por caso las discrepancias detectadas hasta alcanzar un acuerdo total entre los codificadores. 


\section{RESULTADOS}

\subsection{Objetos de estudio en la investigación sobre comunicación}

Siguiendo una tendencia establecida desde la constitución del campo a comienzos de los 70, el periodismo ha continuado siendo el ámbito mediático o profesional predominante en la investigación comunicativa española en el último cuarto de siglo. Para el conjunto de este periodo, prácticamente la mitad (el $46,1 \%$ ) de los artículos analizados trataban aspectos relacionados con el periodismo o la información periodística, con gran diferencia respecto a los dedicados a la comunicación audiovisual (algo más del 20\%), y a mayor distancia aún de la atención dedicada a las relaciones públicas y la comunicación corporativa (en torno al 7\% de los textos) y la publicidad y el márketing (algo más del 5\%) o internet y los medios digitales (alrededor del 8\%), objeto este último que no puede irrumpir hasta mediados de la primera década de los 2000, con el desarrollo y consolidación de la revolución digital. En consecuencia, la investigación sobre comunicación en España continúa siendo un campo disciplinar básicamente decantado hacia los estudios periodísticos.

\section{Gráfico 1. Ámbitos mediático/profesionales objeto de estudio}

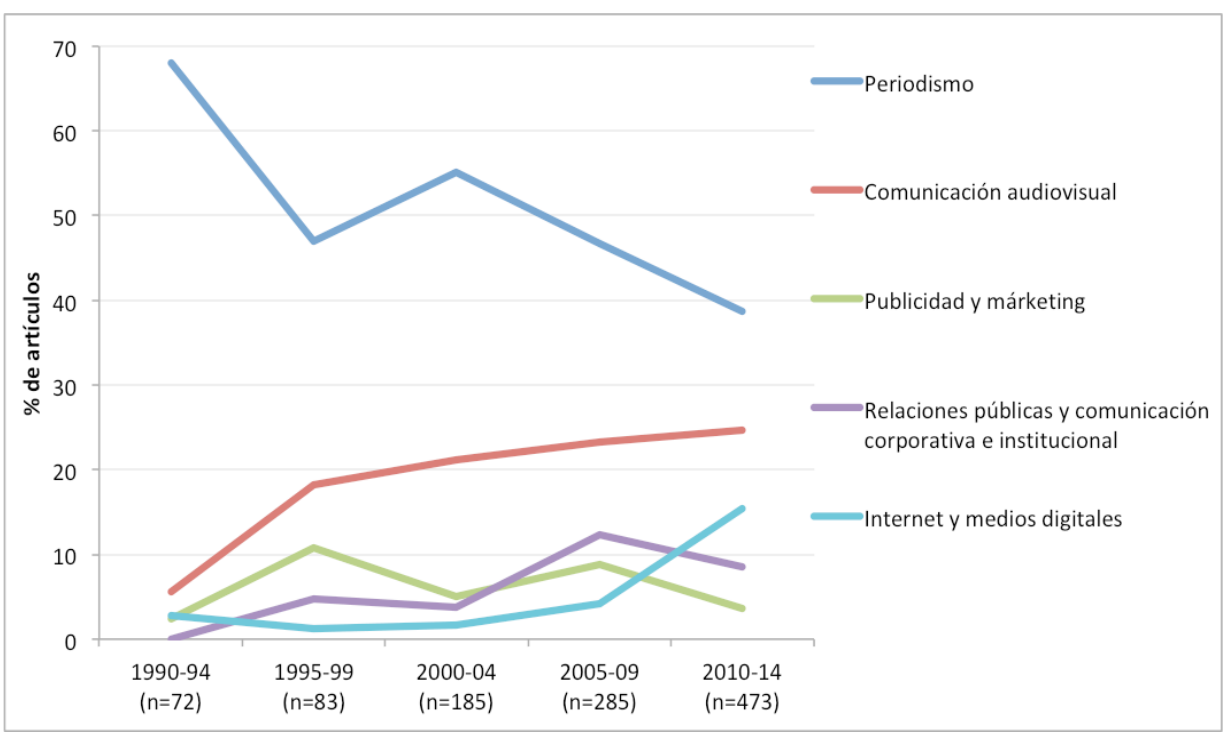


En cualquier caso, si observamos la evolución de esta variable en los últimos 25 años (gráfico 1) puede advertirse en la última década un declive progresivo de la posición predominante del periodismo y la consolidación paulatina del interés por los restantes ámbitos mediático/profesionales. A comienzos del periodo analizado (1990-1994), todavía siete de cada diez artículos publicados por estas revistas eran trabajos sobre periodismo, con una presencia poco menos que residual del resto de estos ámbitos, que no superan en ningún caso el 6\% de los textos. Esa situación comienza a corregirse ya desde mediados de los 90 , pero no será hasta la segunda mitad de la primera década de los 2000 (2005-2009) cuando se acelere con el impulso a la investigación sobre comunicación audiovisual, especialmente, y en menor medida sobre relaciones públicas y comunicación corporativa, sobre publicidad y márketing, y sobre internet y el entorno digital.

Aunque al final del periodo (2010-2014) los estudios periodísticos continúen siendo preeminentes, para entonces representan ya solo en torno al $40 \%$ de los artículos analizados, un 30\% menos que 20 años atrás, con una consolidación clara del interés por la comunicación audiovisual, a la que se adscriben la cuarta parte de los trabajos publicados por estas revistas en la etapa más reciente, y un repunte espectacular de los estudios sobre internet y los medios digitales. Este ámbito se asienta fuertemente en la agenda investigadora en la última década, sumando algo menos del $20 \%$ de los artículos entre 2005 y 2014, pero cuya pujanza va más allá de lo que indica este dato. Si a los que abordan fenómenos específicos del entorno digital (blogs, redes sociales, portales digitales, plataformas audiovisuales en internet, etc.) agregamos aquellos otros que analizan su impacto en los ámbitos mediáticos profesionalizados (periodismo digital, publicidad en la red, webs institucionales y corporativas, etc.), los trabajos centrados en la problemática de la digitalización constituyen en torno al 30\% de los publicados por estas revistas en la última década. En definitiva, la severa corrección del predominio abrumador que tuvieron los estudios sobre periodismo hasta hace no mucho más de diez años indica que a partir de entonces la investigación española sobre comunicación habría entrado en esa situación de relativa normalidad epistemológica que sugieren unos intereses de conocimiento cada vez más diversificados, y una comunidad científica progresivamente especializada para atender la complejidad del ecosistema comunicativo contemporáneo.

No obstante, si observamos esos intereses a partir de los elementos del proceso de comunicación (emisores, contenidos, audiencias, efectos, etc.) atendidos por los investigadores, comprobamos que la actividad científica en este campo habría estado tradicionalmente escorada hacia el análisis de la dimensión discursiva de la comunicación (contenidos), muy por encima del esfuerzo dedicado a sus dimensiones institucional (empresas, profesionales, políticas públicas, etc.) y social (audiencias, usuarios, efectos e influencia de los medios, etc.). Para el conjunto del periodo analizado, los estudios sobre contenidos (coberturas informativas, representaciones de cualquier tema o sector de la población -mujeres, jóvenes, inmigrantes, etc.- en las noticias, la ficción televisiva o en la publicidad, análisis de webs corporativas o institucionales, etc.) constituyen la mitad de los artículos incluidos en la muestra (el 49,6\%), a gran distancia de aquellos 
que abordan aspectos referidos a los profesionales (perfiles laborales, formación, rutinas de trabajo, códigos deontológicos, asociaciones, etc.), que son solo el 17,3\%; las empresas e instituciones (organización, funcionamiento, mercados, políticas públicas, etc.), el 16,1\%; o las audiencias y usuarios (composición, uso de medios y tecnologías, actividad de recepción, etc.), el 13,7\% de los textos.

\section{Gráfico 2. Objetos de estudio específicos}

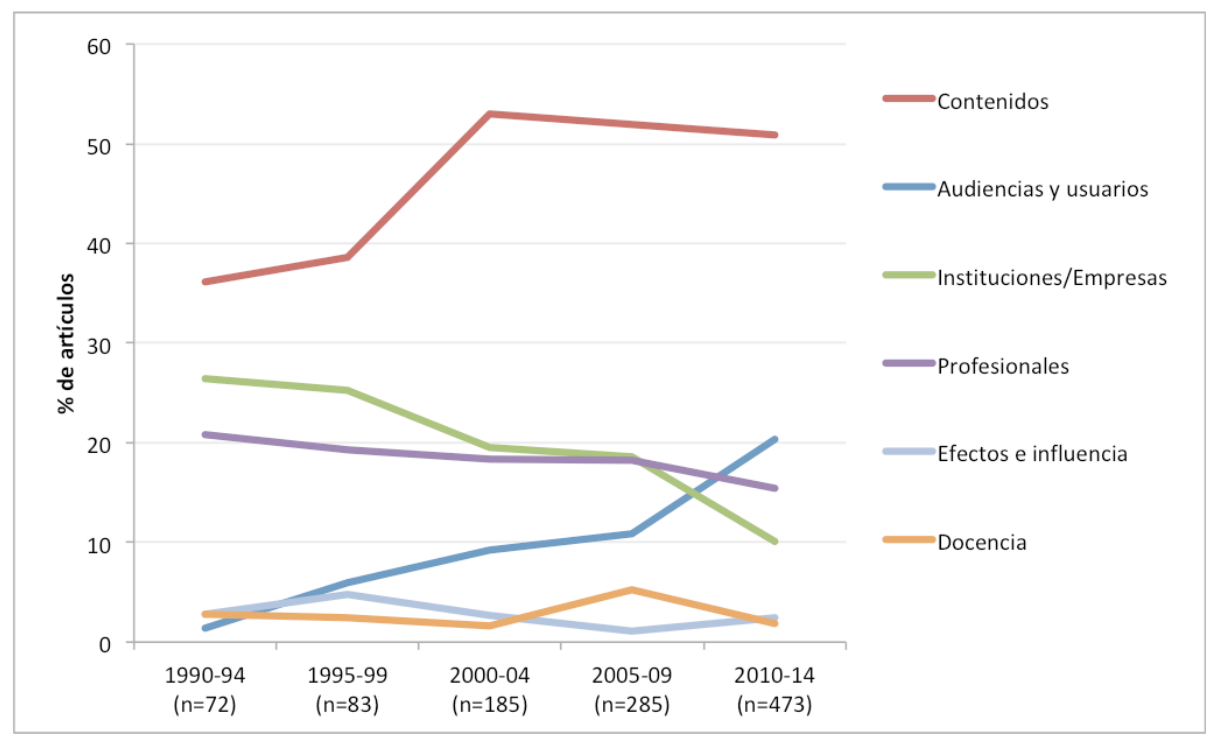

Sorprendentemente, ese sesgo contenidista permanece prácticamente inalterado en los últimos 15 años (gráfico 2). Durante la década de los 90 todavía podía observarse un cierto equilibrio en la atención investigadora a estos distintos objetos, de modo que prácticamente cuatro de cada diez artículos se centraban en los contenidos, pero cinco de ellos lo hacían en aspectos relativos a los ámbitos empresarial/institucional y profesional, con una presencia incipiente de los trabajos dedicados al análisis de audiencias y usuarios (en torno al 6\% de los artículos). Esa distribución más o menos equilibrada se rompe abruptamente desde la década siguiente, ya en los años 2000, y a partir de entonces el estudio de los contenidos alcanza una posición de preeminencia absoluta en la investigación comunicativa española, llegando a representar continuadamente más del 50\% de los trabajos que publican las revistas analizadas, con una desatención, ya muy acusada en la etapa más reciente (2010-2014), por las problemáticas referidas a la dimensión institucional de la comunicación, que en conjunto apenas superan el 25\% de los artículos en ese periodo. A mediados de los 2000 (quinquenio 2005-2009) repunta algo la investigación sobre la docencia universitaria (planes de estudio, prácticas docentes, uso de nuevas herramientas pedagógicas, etc.), 
pero se trata de un interés sin continuidad, motivado por la adaptación de las titulaciones de comunicación al Espacio Europeo de Educación Superior (el plan Bolonia). Más significativa es la consolidación de los estudios sobre audiencias y usuarios, claramente establecidos desde inicios de los 2000, y que se incrementan decididamente ya en el último quinquenio (2010-2014), impulsados por el interés en las nuevas prácticas comunicativas emprendidas por las audiencias de manera autónoma -esto es, al margen de los medios profesionales- en el entorno digital (uso de redes sociales, blogs, etc.) y por los procesos de apropiación de las tecnologías digitales por parte de los usuarios. En cuanto al análisis de los efectos y la influencia de la comunicación, un área tradicional en la investigación comunicativa internacional desde sus inicios, parece haber estado ausente de la agenda investigadora española en el campo en los últimos 25 años, con una aportación que llega solo al 2,3\% de los artículos incluidos en la muestra.

\subsection{Tipos de investigación en los estudios sobre comunicación}

Los datos indican que los trabajos publicados por estas revistas han sido, en un volumen abrumador, investigaciones empíricas, que constituyen casi el $80 \%$, con una presencia bastante discreta (solo en torno al 18\%) de aquellas otras de carácter teórico-conceptual, y prácticamente nula $(2,4 \%)$ de las de tipo metodológico. Cabe inferir, por tanto, que la investigación española en este periodo se ha decantado fundamentalmente hacia el estudio de la propia realidad fenoménica de la comunicación, habiendo estado menos interesada en la reflexión y discusión relativa a los enfoques, perspectivas y métodos desde lo que conduce la generación del conocimiento científico en el campo.

\section{Gráfico 3. Tipo de investigación}

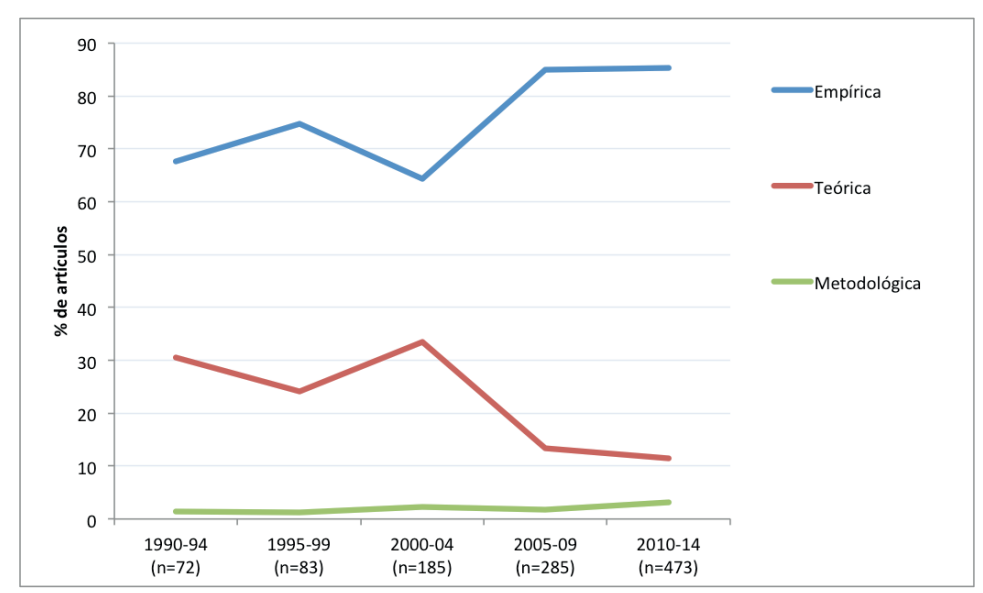


Si atendemos a la evolución de estas categorías (gráfico 3), podemos observar que el predominio de la investigación empírica se afianza de manera radical en la última década (2005-2014), en donde supone ya el 85\% de los artículos publicados por estas revistas. En los quince años precedentes, entre 1990 y 2004, en torno a siete de cada diez artículos publicados eran de índole empírica, pero todavía tres de ellos eran trabajos que abordaban problemáticas teóricas o estados de la cuestión sobre objetos particulares de la investigación comunicativa. En los últimos diez años, como decimos, esa tendencia, hasta entonces estable, se rompe inopinadamente, de manera que en esta etapa más reciente la investigación teórica decae en estas revistas hasta unos niveles meramente testimoniales, con apenas el $10 \%$ de los textos.

\section{Gráfico 4. Tipo de investigación empírica}

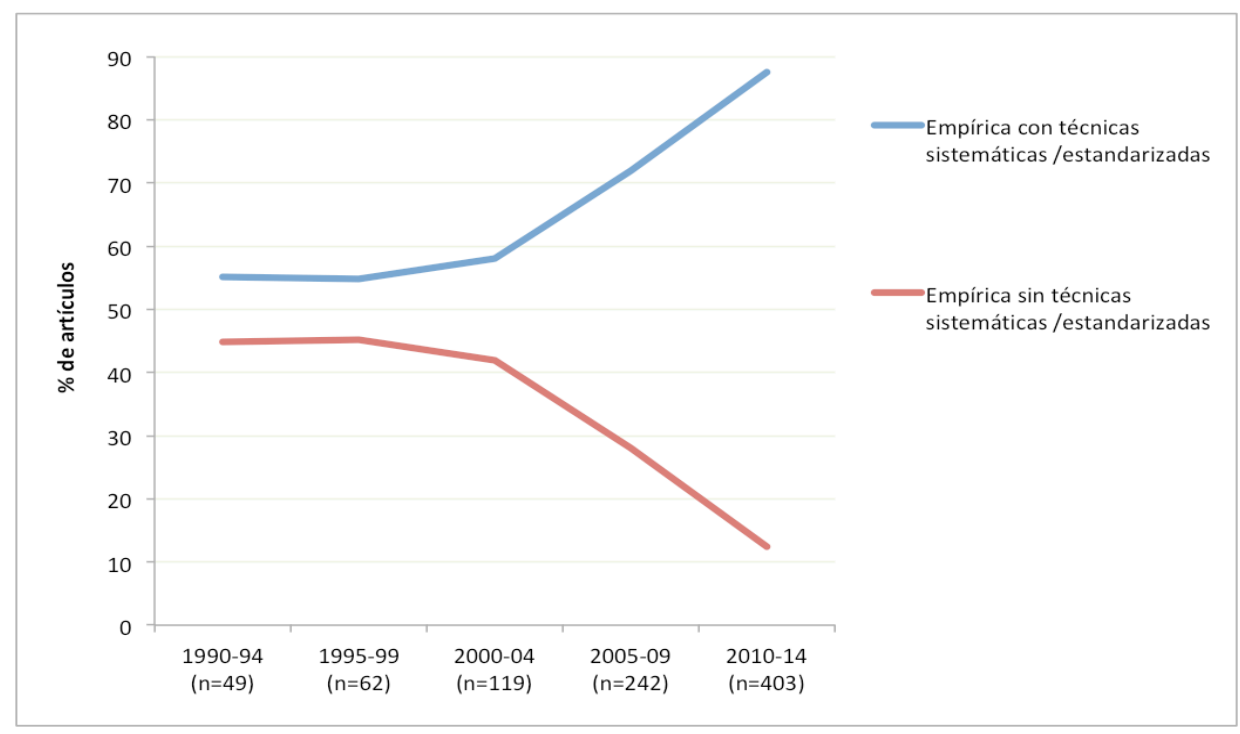

El reforzamiento reciente de esa vocación empírica ha venida acompañada de una significativa mejora, al menos indiciaria, de la calidad metodológica de los trabajos publicados (gráfico 4). En el fragmento muestral correspondiente a los 15 años que van de 1990 a 2004, prácticamente la mitad de las investigaciones sobre objetos empíricos (estudios sobre contenidos, profesiones, empresas, audiencias, etc.) no apoyaban sus resultados en datos obtenidos mediante el recurso a técnicas sistemáticas o estandarizadas (ya fuese el análisis de fuentes documentales o aquellas otras usuales en la investigación social: análisis de contenido o discursivo, encuestas, grupos de discusión, etc.), por lo que debieran tenerse, como ya comentamos, por metodológicamente deficientes. Esa situación 
de insuficiencia metodológica generalizada comienza a corregirse desde hace una década, decayendo a niveles algo más tolerables (si es que hubiese margen para la tolerancia metodológica en la actividad científica) en el quinquenio 2005-2009, y más aún en el siguiente, en donde suponen ya solo uno de cada diez de los analizados. Como decíamos, esta mejora metodológica es meramente indiciaria, ya que para este trabajo no se evaluó el grado en que el recurso a esos métodos y técnicas se ajustaba a los protocolos normativizados por la literatura metodológica (sobre la correcta aplicación de diseños muestrales, instrumentos para el acceso a los datos, procedimientos de trabajo de campo, modalidades de análisis de datos y presentación de resultados, etc.). Pero, en cualquier caso, parece evidente que, en este aspecto crucial de la observancia de los criterios metodológicos que garantizan el rigor en la producción científica, el esfuerzo formativo realizado por los investigadores españoles en el campo, y el de las propias revistas reforzando los controles sobre lo publicado, debe ser convenientemente apreciado, y en la etapa más reciente (quinquenio 2010-2014) ya casi el 90\% de los artículos analizados presenta indicios de una calidad metodológica suficiente.

\section{Gráfico 5. Tipo de investigación empírica con técnicas sistemáticas}

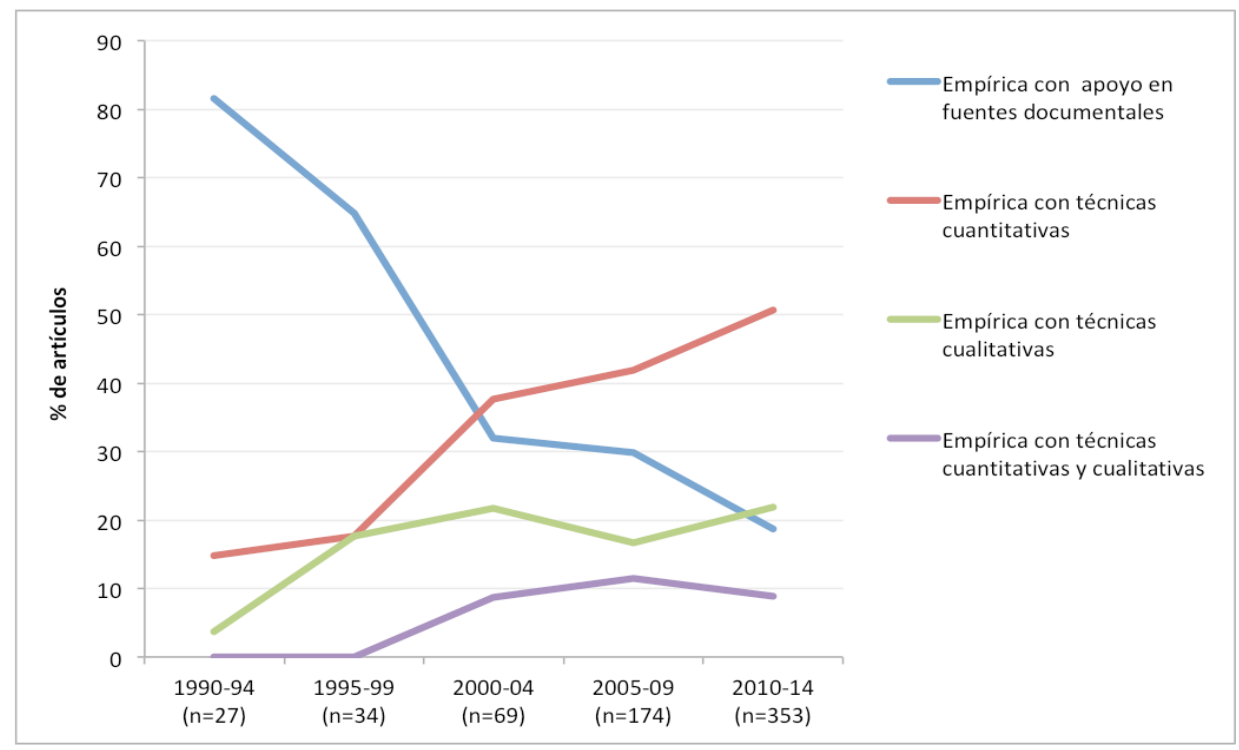

Por lo que hace a esta investigación empírica cualificada (es decir, aquella que utiliza técnicas sistemáticas), se observa igualmente un significativo cambio de tendencia conforme ha ido avanzando el periodo analizado (gráfico 5). En la década de los 90, tres de cada cuatro de estos trabajos se apoyaban en datos obtenidos mediante el análisis de fuentes documentales (archivos históricos, 
informes empresariales o de otras instituciones públicas o privadas, sentencias judiciales, códigos deontológicos, estatutos o disposiciones de asociaciones profesionales, etc.), y solo en torno al 25\% restante recurría a las técnicas características de la investigación social, fuesen de índole cuantitativa (encuesta, análisis de contenido, etc.) o cualitativa (entrevista, grupos de discusión, análisis discursivo, etc.). En los últimos 15 años, el peso relativo de esta investigación documental -por lo general, aunque no solo, presente en áreas tradicionalmente vinculadas a las humanidades: historia de la comunicación, análisis fílmico, etc.- parece decaer en el conjunto de la investigación comunicativa española, reemplazada en esa posición predominante por la pujanza que adquiere a partir de entonces el recurso a las técnicas propias de las ciencias sociales. En la última década (2005-2014), ya más del 75\% de los artículos empíricos analizados son estudios cuantitativos o cualitativos con técnicas asociadas a estos métodos, con un incremento considerable de los primeros en la etapa más reciente (20102014), superando ya en estas revistas el 50\% de esta investigación metodológicamente cualificada.

\subsection{Técnicas de investigación y fuentes de datos en la investigación comunicativa}

El tipo de técnicas empíricas utilizadas en esos trabajos metodológicamente cualificados es consecuente con el predominio de la dimensión discursiva de la comunicación entre los intereses de conocimiento de la comunidad científica. Dejando aparte la relevancia que tuvo durante la década de los 90 la investigación apoyada en fuentes documentales, la técnica más frecuente en la muestra estudiada es el análisis de contenido cuantitativo, a la que se recurre casi en la tercera parte de los artículos publicados en los últimos 25 años por estas revistas, más del doble de los que lo hacen a cualquiera de las diferentes modalidades del análisis del discurso (sociológico, semiótico, argumentativo, narratológico, crítico, etc.), empleado en alrededor del $15 \%$ de los textos, y a la encuesta, con un porcentaje similar. El uso de las restantes técnicas es solo ocasional (la entrevista en profundidad y el análisis secundario, en alrededor del 8\% de los artículos; y el grupo de discusión, en el 5\%), o claramente testimonial (los diseños experimentales, solo en el 2,6\%; y otras técnicas cualitativas -observación etnográfica, métodos biográficos, Delphi-, utilizadas en poco más del 3\% de esos artículos). 


\section{Gráfico 6. Técnicas de investigación empírica}

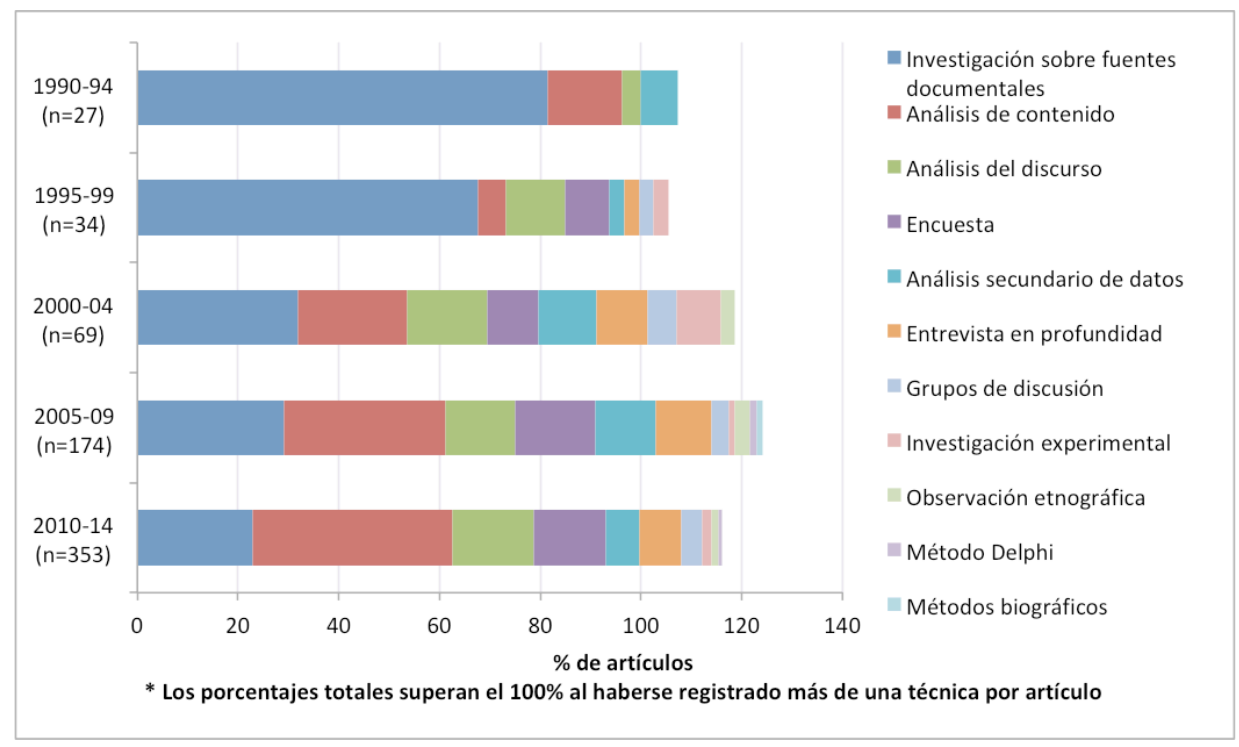

Los datos obtenidos indican que el análisis de contenido comienza a asentarse de manera predominante en la investigación comunicativa española en la última década, desde mediados de los 2000 en adelante (gráfico 6), siguiendo, además, una tendencia ascendente, con cerca del $40 \%$ de los artículos en el quinquenio 2010-2014, prácticamente doblando el registro de diez años atrás. Siendo incuestionable esa preeminencia, la evolución de este parámetro revela, no obstante, una progresiva diversificación metodológica, con la ampliación paulatina del acervo de técnicas empíricas al que ha ido recurriendo la investigación en este campo, y que alcanza el punto de máxima diversidad justamente también en la última década, en donde se registra la práctica totalidad de las categorías incluidas, aunque algunas de ellas, como decíamos, con una presencia escasa. 


\section{Gráfico 7. Fuentes de datos en la investigación empírica}

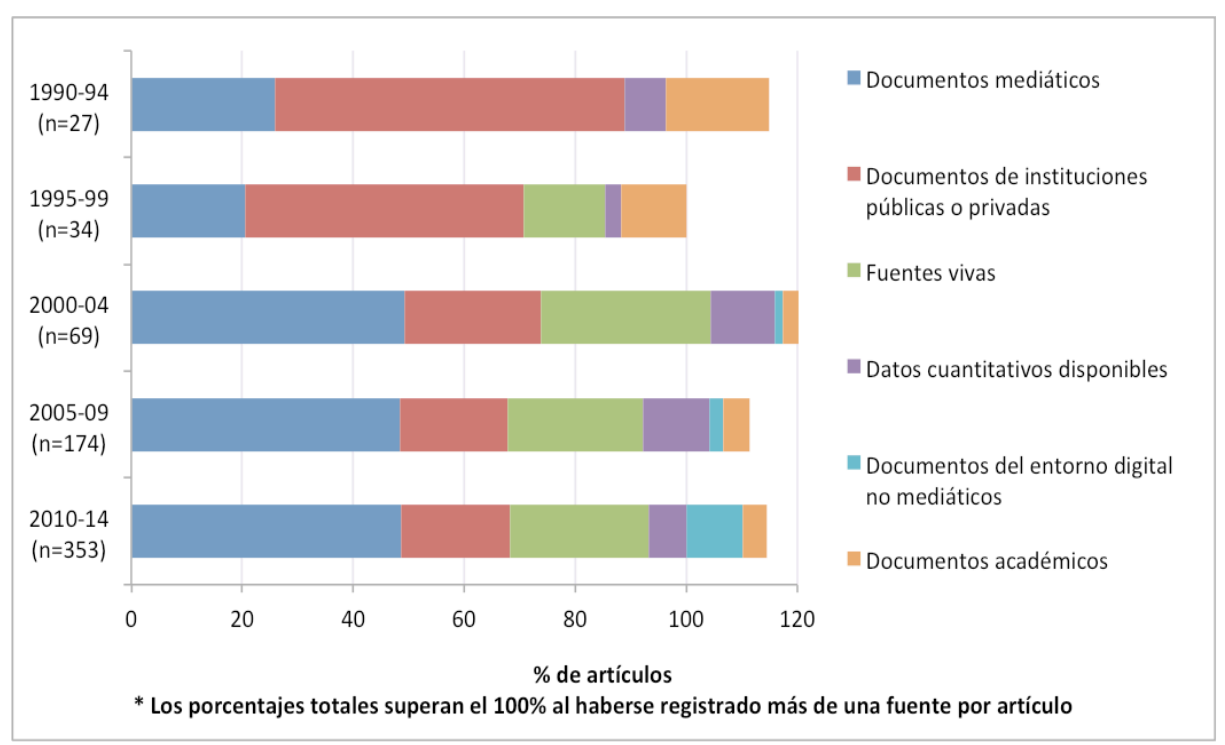

Algo similar sucede con las fuentes de datos en la investigación empírica (gráfico 7). En consecuencia con el predominio de los estudios sobre contenidos, tres de cada cuatro trabajos publicados por estas revistas en los últimos 25 años (el 77\%) apoyan sus resultados en datos de naturaleza documental, y solo poco más de la cuarta parte (el 27,4\%) recurre a fuentes vivas (personas) accesibles mediante técnicas como la encuesta, los diseños experimentales, la entrevista, el grupo de discusión o la observación etnográfica. Ciertamente, el comportamiento de esta variable revela también el uso de una progresiva diversidad de fuentes documentales en los artículos analizados, pero con un predominio indiscutible desde inicios de los años 2000 de las de origen mediático (noticias, anuncios, series televisivas, películas, etc.), y una incorporación, ya decidida en la etapa mas reciente, de aquellas otras propias del entorno digital no vinculado a los medios profesionales (blogs, documentos -tweets, posts, fotografías, vídeosdistribuidos en las redes sociales, etc.). Y puede apreciarse, asimismo, cómo el recurso a fuentes vivas, inexistente en la etapa inicial (1990-1994), va ganando espacio con una presencia regular en los últimos 15 años, que ronda el 30\% de los trabajos publicados en este periodo. 


\section{DISCUSIÓN Y CONCLUSIONES}

El análisis de los objetos de estudio atendidos y de los dispositivos metodológicos utilizados en los artículos publicados en revistas académicas especializadas en el último cuarto de siglo permite reconstruir aspectos centrales de las tendencias epistemológicas en las que se habría movido la investigación sobre comunicación en España en ese periodo. En este trabajo se han abordado estas cuestiones mediante un análisis de contenido de una muestra de 1.098 artículos incluidos en seis revistas españolas entre 1990 y 2014. Aunque esa muestra no es, desde luego, estadísticamente representativa de la totalidad de la investigación comunicativa generada en esos 25 años, sí lo sería de aquella de mayor relevancia e influencia en el campo, dado el carácter referencial de las publicaciones seleccionadas aplicando criterios de impacto bibliométrico y de prestigio entre los investigadores. Los resultados obtenidos serían, por tanto, un indicador idóneo para dilucidar aquellas tendencias con un fundamento empírico suficiente.

Se ha observado, en primer lugar, una progresiva diversificación de los intereses de conocimiento de la comunidad científica dedicada al desarrollo de este ámbito disciplinar, muy escorada al inicio del periodo hacia el estudio del periodismo, pero que va dando cabida paulatinamente a problemáticas relativas a otros ámbitos mediáticos y profesionales. Siguiendo una inercia heredada del momento fundacional del campo con la creación de las primeras facultades especializadas (significativamente denominadas de Ciencias de la Información), el predominio abrumador de los estudios sobre periodismo en la década de los 90 va aminorándose con el tiempo, incrementándose el peso relativo de los trabajos que atienden aspectos relacionados con la comunicación audiovisual, la publicidad y el márketing, las relaciones públicas y, en la etapa final, internet y el entorno digital. Según indican los datos obtenidos, la investigación en estas otras áreas arrancaría en la segunda mitad de los 90 -excepto en lo relativo a internet, obviamente-, lo cual coincide con la evidencia disponible sobre la evolución en las facultades españolas de las tesis doctorales sobre comunicación audiovisual, publicidad y relaciones públicas, que despegan justamente en ese momento, indicando claramente la consolidación de esos ámbitos en la investigación comunicativa española (Repiso, Torres y Delgado, 2011a y 2011b, sobre radio y televisión; Marcos, Martínez Pestaña y Blasco, 2012, sobre publicidad; Castillo y Xifra, 2006, sobre relaciones públicas). A esa consolidación probablemente contribuyó la decisión, a comienzos de los 90, de fragmentar la antigua licenciatura en Ciencias de la Información en tres titulaciones -en Periodismo, en Comunicación Audiovisual, y en Publicidad y Relaciones Públicas-, generando así nichos académicos autónomos que permitieron diversificar la comunidad científica, y con ello la investigación, en unas facultades que no en vano mudaron entonces su denominación a la más inclusiva de Ciencias de la Comunicación (Martínez Nicolás, 2008).

La ampliación paulatina de los intereses científicos que sugieren estos resultados contrasta con la tendencia, muy reforzada con el paso del tiempo, a concentrar el esfuerzo investigador en la dimensión discursiva de la comunicación. 
El análisis de los contenidos mediáticos ha sido, en efecto, el objeto de estudio preponderante en la investigación comunicativa española publicada por estas revistas en el periodo analizado, pero su peso relativo durante la década de los 90 era todavía menor que el conferido conjuntamente a las restantes dimensiones de los procesos comunicativos, sobre todo a la institucional (empresas, mercados, políticas sectoriales, profesiones, mecanismos y rutinas de producción, etc.). Ese cierto equilibrio en los intereses de investigación se rompe abruptamente desde inicios de los 2000, cuando los trabajos centrados en los contenidos, y especialmente en los mediáticos (coberturas informativas, representación de temas o de sectores de la población en las noticias, la publicidad o en la ficción televisiva o cinematográfica, etc.), supera la mitad de los artículos publicados por estas revistas.

Resulta sorprendente el decaimiento relativo en los últimos 15 años de la atención que la comunidad científica ha venido prestando a la dimensión institucional de la comunicación, que para el conjunto de las categorías temáticas aquí consideradas se sitúa en torno al 30\% de los artículos analizados, casi un $20 \%$ menos de los que se dedicaban a estas cuestiones en la década de los 90 . Y resulta sorprendente, decimos, porque esa relativa desatención se produce en un contexto socio-histórico caracterizado por la radical transformación del sector de la comunicación con el advenimiento de la digitalización, que está alterando severamente el funcionamiento y organización de las empresas mediáticas, los mercados de la comunicación, las políticas públicas sectoriales, y los perfiles, competencias profesionales y procesos de trabajo en estas industrias culturales. Pareciera que un contexto de tal riqueza fenomenológica debería haber impulsado decididamente la investigación en este ámbito, por lo que ese retraimiento sugiere que la investigación española no estaría respondiendo de manera adecuada a demandas de conocimiento perentorias para el sistema comunicativo contemporáneo, encerrada en el estudio de los productos mediáticos (los contenidos) y descuidando el análisis de las condiciones de su producción (empresas, instituciones, profesionales, etc.).

En una tendencia que se dispara en la última década (2005-2014), la investigación española sobre comunicación refuerza la vocación empírica que habría tenido en los 25 años analizados, pero eso hasta el punto de que en esta etapa más reciente los trabajos de carácter teórico-conceptual acaban teniendo una presencia casi testimonial en las revistas seleccionadas (apenas uno de cada diez artículos), reduciendo drásticamente un peso que en los tres lustros precedentes llegó a alcanzar el 30\% de los trabajos publicados. Estaríamos, por tanto, ante una comunidad científica claramente volcada en el análisis de la propia realidad fenoménica de la comunicación -aunque con ese evidente sesgo contenidista que también advierten Lozano y Gaitán (2016) en las preferencias metodológicas de los investigadores en el periodo más reciente-, pero poco implicada, al parecer, en la reflexión y discusión de las teorías, conceptos, enfoques heurísticos y herramientas metodológicas con los que se genera el conocimiento científico, algo que debiera ser permanentemente revisado en ese ejercicio de vigilancia 
epistemológica que se reclama en cualquier disciplina (Bourdieu, Chamboredon y Passeron, 1973; Vassallo de Lopes, 1990).

El refuerzo de esa orientación empírica en los últimos diez años habría venido acompañado, al menos indiciariamente, de una mejora en la calidad metodológica de este tipo de trabajos. Hasta mediados de la primera década de los 2000, prácticamente la mitad de los artículos empíricos analizados fueron considerados metodológicamente deficientes por no fundamentar sus resultados en datos apoyados en una exploración adecuada de fuentes documentales u obtenidos mediante técnicas sistemáticas propias de las ciencias sociales (análisis de contenido, encuesta, grupos de discusión, etc.). Esa situación de anemia metodológica comienza a corregirse en el quinquenio 2005-2009 y continúa en la etapa más reciente (2010-2014), en que los trabajos que revelan una mala praxis investigadora se reducen a solo algo más del 10\% de los analizados, un resultado que coincide con el obtenido por Castillo, Almansa y Álvarez Nobell (2013) para el periodo 2000-2012.

La investigación comunicativa española parece haber entrado en la última década en una etapa de relativa normalidad, atenta ya a los estándares establecidos por la comunidad científica para garantizar el rigor y la validez del conocimiento. Probablemente no sea casual que ese incremento de la cualificación de los trabajos empíricos coincida con la decidida apertura de los investigadores españoles en este campo a la publicación en revistas internacionales de referencia (Masip, 2011; De Filippo, 2013; Fernández Quijada, Masip y Bergillos, 2013; Martínez Nicolás, 2014), de alto valor curricular a la hora de emprender y consolidar una carrera universitaria tras la puesta en marcha por parte de la ANECA en 2008 del programa Academia de acreditación del profesorado. La indudable exigencia metodológica que conlleva el acceso a esas revistas, junto a los nuevos programas de formación investigadora en los másteres implantados con la adaptación al Espacio Europeo de Educación Superior (Castillo, Álvarez Nobell y Muñiz, 2013), explicaría ese salto de calidad de la investigación comunicativa española, que se dejaría sentir también, lógicamente, en los trabajos publicados por las revistas españolas especializadas.

En ese mismo movimiento de apertura, es posible también que la investigación en este ámbito se haya visto impelida a adoptar los estándares y orientaciones de ese paradigma con vocación hegemónica que estarían promoviendo y afianzando las revistas internacionales de referencia en el campo (CarrascoCampos y Saperas, 2014 y 2016). Esta situación se advertiría en el predominio que en la última década han ido adquiriendo en la investigación comunicativa española los trabajos de tipo cuantitativo, que ya representan en el quinquenio más reciente (2010-2014) algo más de la mitad de los artículos analizados. En esta última etapa decae también, y de forma drástica, el peso relativo de la investigación apoyada en fuentes documentales (archivos históricos y, en general, la diversa tipología de documentos generados por instituciones políticas, empresariales, profesionales, judiciales, etc.), indicativo, quizá, de una investigación en la que el tradicional predominio de los planteamientos humanísticos va cediendo en favor de aquellos otros vinculados a las ciencias sociales. 
En consonancia con la centralidad de la dimensión discursiva de la comunicación entre los intereses de la comunidad científica, el perfil típico, o más frecuente al menos, en la investigación comunicativa española de la última década es el de un trabajo empírico en el que se estudia algún producto mediático o del entorno digital (noticias, anuncios, series televisivas, películas, páginas web, intervenciones en redes sociales, etc.) mediante un análisis de contenido cuantitativo. En el periodo más reciente (2010-2014), los artículos con este perfil suponen ya casi cuatro de cada diez de los publicados por las revistas seleccionadas, prácticamente doblando su volumen relativo con respecto al quinquenio 2000-2004 (poco más del 20\%). El desinterés paulatino por la dimensión institucional (empresas, profesionales, etc.) de los procesos comunicativos, y la atención solo incipiente, registrada en el último quinquenio, por la dimensión social (especialmente en lo relativo a la actividad de audiencias y usuarios) explicaría el limitado uso de técnicas para el acceso a fuentes vivas (personas), refrendando esa imagen de una investigación comunicativa reacia a pisar la calle y cómodamente instalada en las prácticas de la desk research que ya advertimos en otra ocasión (Martínez Nicolás y Saperas, 2011), y que no parece remitir con el paso del tiempo.

Es posible que esa fuerte decantación hacia el estudio cuantitativo de los contenidos obedezca a motivos meramente pragmáticos, en razón de la facilidad de acceso a unas fuentes de datos por lo general disponibles en repositorios digitalizados, y que exigen, por tanto, de un despliegue de recursos (entre ellos, el de uno crecientemente valioso, el tiempo) de menor envergadura que el requerido para el abordaje de otros objetos de estudio y el empleo de otras técnicas empíricas. Pero en un contexto académico de altísima presión por publicar, endurecido desde la implantación en 2008 del programa Academia de acreditación del profesorado universitario, las decisiones de los investigadores sobre objetos que atender y métodos que aplicar parecen estar orientándose cada vez más por criterios de estricta rentabilidad curricular del esfuerzo invertido. Y eso, como parecen indicar las tendencias detectadas en este trabajo, a riesgo de ir reduciendo el ecosistema de la investigación comunicativa española al monocultivo del análisis cuantitativo de contenidos.

\section{BIBLIOGRAFÍA}

ABUíN, N. (2010): "Los estudios de comunicación en España”, en H. Vivar (coord.), Los estudios de comunicación en España. Reflexiones en torno al Libro Blanco, Madrid, Icono 14, pp. 31-53.

ANECA (2005): Libro blanco de las titulaciones de Grado en Comunicación, Madrid, Agencia Nacional de Evaluación de la Calidad y Acreditación (ANECA).

ARCEO, J. L. (2006): "La investigación sobre relaciones públicas en España”, Anàlisi. Quaderns de Comunicació i Cultura, 34, pp.111-124. 
BALADRÓN, A. J.; CORREYERO, B. y MANCHADO, B. (2014): "Three decades of advertising research in Spain: Analysis of scientific communication journals (19802013)", Communication \& Society, 27 (4), pp. 49-71.

BALADRÓN, A. J.; MANCHADO, B. y CORREYERO, B. (2017): "Estudio bibliométrico sobre la investigación en publicidad en España: temáticas, investigadores, redes y centros de producción (1980-2015)", Revista Española de Documentación Científica, 40 (2).

BARRANQUERO, A. y LIMÓN, N. (2017): “Objetos y métodos dominantes en comunicación para el desarrollo y el cambio social en las Tesis y Proyectos de Investigación en España (2007-2013)", Revista Latina de Comunicación Social, 72, pp. 1-25.

BORRAT, H. (1990): "El debat entre professionalistes i comunicòlegs", Annals del Periodisme Català, 16, pp. 54-63.

BOURDIEU, P.; CHAMBOREDON, J. C. y PASSERON, J. C. (1973): El oficio de sociólogo. Presupuestos epistemológicos, Buenos Aires, Siglo XXI, 1975.

CARRASCO-CAMPOS, Á. y SAPERAS, E. (2014): "Debate, confrontación y hegemonía en la disciplina de la comunicación. Nuevos tiempos para un paradigma dominante", Redes.com, 10, pp. 145-158.

CARRASCO-CAMPOS, Á. y SAPERAS, E. (2016): “Cambio tecnológico, globalización neoliberal y hegemonías metodológicas en la investigación comunicativa internacional", Ámbitos. Revista Internacional de Comunicación, 32.

CASTILLO, A. y CARRETÓN, M. C. (2010): "Investigación en Comunicación. Estudio bibliométrico de las Revistas de comunicación en España", Comunicación y Sociedad, 23 (2), pp. 289-327.

CASTILLO, A. y XIFRA, J. (2006): «Investigación bibliométrica de las tesis doctorales españolas sobre de relaciones públicas (1965-2005)", Anàlisi. Quaderns de Comunicació i Cultura, 34, pp. 111-124.

CASTILlO, A.; ALMANSA, A. y ÁlVAREZ NOBELL, A. (2013): "Metodología científica en las revistas españolas de comunicación", en M. Vicente Mariño, T. González Hortigüela y M. Pacheco (coords.) (2013), Investigar la comunicación, hoy: revisión de políticas científicas y aportaciones metodológicas. Actas del II Congreso Nacional sobre Metodología de la Investigación en Comunicación, Segovia, Asociación Española de Investigación de la Comunicación, pp. 107-121.

CASTILLO, A.; ÁLVAREZ NOBELL, A. y MUÑIZ, J. A. (2013). "EEES y la formación de comunicación en España. Estructura de la oferta de posgrado", Estudios sobre el Mensaje Periodístico, volumen 19 (número especial, marzo), pp. 99-110.

CIVIL, M. (2018): "Los estudios universitarios de comunicación en España (2017). Análisis de la situación actual para un debate abierto sobre su futuro estratégico", en I. Postigo y M. J. Recoder (coords), Los y las «tics» en los estudios de comunicación, Málaga, Asociación Española de Universidades con Titulaciones de Información y Comunicación, pp. 15-85.

DE FILIPPO, D. (2013): "La producción científica española en Comunicación en WOS. Las revistas indexadas en SSCI (2007-12)", Comunicar. Revista Científica de Comunicación y Educación, 21, pp. 25-34.

DE MIGUEL, R. (2007): “Sociología de la comunicación”, en M. Pérez Iruela (comp.), La sociología en España, Madrid, Centro de Investigaciones Sociológicas y Federación Española de Sociología, pp. 583-607.

ESCRIBÀ, E. y CORTIÑAS, S. (2013): "La internacionalización y las coautorías en las principales revistas científicas de Comunicación en España", Comunicar. Revista Científica de Comunicación y Educación, 21, pp. 35-44. 
FERNÁNDEZ QUIJADA, D. y MASIP, P. (2013): "Tres décadas de investigación española en comunicación: hacia la mayoría de edad", Comunicar. Revista Científica de Comunicación y Educación, 41, pp. 15-24.

FERNÁNDEZ QUIJADA, D.; MASIP, P. y BERGILLOS, I. (2013): "El precio de la internacionalidad: la dualidad en los patrones de publicación de los investigadores españoles en comunicación”, Revista Española de Documentación Científica, 36 (2), e010.

FERNÁNDEZ VISO, A. (2012): "Historia de una travesía inconclusa: la comunicación para el desarrollo y el cambio social en la investigación y la docencia universitarias en España”, Cuadernos de Información y Comunicación, 17, pp. 41-62.

GAITÁN, J. A.; LOZANO, C. y PIÑUEL, J. L. (2016): "Prospectiva de la investigación sobre TV a partir de los proyectos de I+D y Tesis doctorales de 2007 a 2013 en las Facultades españolas de comunicación”, Revista de la Asociación Española de Investigación sobre Comunicación, 6, pp. 51-59.

GARCÍA JIMÉNEZ, L. (2007): Las teorías de la comunicación en España: un mapa sobre el territorio de nuestra investigación (1980-2006), Madrid, Tecnos.

GOYANES, M. (2017): Desafío a la investigación estándar en comunicación. Crítica y alternativas, Barcelona, Editorial Universitat Oberta de Catalunya.

GOYANES, M. y PEINADO, F. (2014): "Online newspapers business models in Spanish scientific journals. A review and suggestions for future research", Ámbitos. Revista Internacional de Comunicación, 24, pp. 91-100.

HUMANES, M. L. (2007): "La investigación sobre la profesión periodística en España", Sphera Pública, número extraordinario: La investigación de la comunicación en Iberoamérica: historia, estado actual y nuevos retos, pp.173-193.

IDOYAGA, J. (1990): "Communication sociale et enseignement universitaire en Espagne”. Médiaspouvoirs, 17, pp. 109-114.

JONES, D. E. (1998): "Investigación sobre comunicación en España. Evolución y perspectivas", Zer. Revista de Estudios de Comunicación, 5, pp. 13-51.

LACASA, I. (2017): "Die spanische Kommunikationswissenschaft auf dem Weg zu internationaler Anerkennung. Ein Abriss der Fachgeschichte“, en S. Averbeck (ed.), Kommunikationswissenschaft im internationalen Vergleich. Transnationale Perspektiven, Berlín, Springer, pp. 185-210.

LASSWELL, H. (1948): "Estructura y función de la comunicación en al sociedad", en M. de Moragas (ed.), Sociología de la comunicación de masas, volumen 2: "Estructura, funciones y efectos", Barcelona, Gustavo Gili, 1985, pp. 50-60.

LÓPEZ ESCOBAR, E. y MARTÍN ALGARRA, M. (2017): "Communication teaching and research in Spain: The calm and the storm", Publizistik, 62 (1), pp. 83-105.

LÓPEZ RABADÁN, P. y VICENTE MARIÑO, M. (2011): "Métodos y técnicas de investigación dominantes en las revistas científicas españolas sobre comunicación (2000-2009)", en J. L. Piñuel, C. Lozano y A. García Jiménez (eds.), Investigar la comunicación en España, Madrid, Asociación Española de Investigación de la Comunicación, pp. 665-679.

LOZANO, C. y GAITÁN, J. A. (2016): "Vicisitudes de la investigación en comunicación en España en el sexenio 2009-2015", Disertaciones. Anuario Electrónico de Estudios en Comunicación Social, 9 (2), pp. 139-162.

MARCOS, J. C; MARTÍNEZ PESTAÑA, M. J. y BLASCO, M. F. (2012): „Producción y dirección de tesis doctorales sobre publicidad en la universidad española (19712010), Revista Española de Documentación Científica, 35 (3), pp. 433-452. 
MARÍ, V. (2017): "Historia de la Comunicación para el Desarrollo y el Cambio Social en España. Marginalidad, institucionalización e implosión de un campo en crecimiento", Telos. Revista de Pensamiento sobre Comunicación, Tecnología y Sociedad, 106, pp. 27-38.

MARTÍNEZ NICOLÁS, M. (2006): "Masa (en situación) crítica. La investigación sobre periodismo en España: comunidad científica e intereses de conocimiento", Anàlisi. Quaderns de Comunicació i Cultura, 33, pp. 135-170.

MARTÍNEZ NICOLÁS, M. (2008): "La investigación sobre comunicación en España. Evolución histórica y retos actuales", en M. Martínez Nicolás (ed.), Para investigar la comunicación. Propuestas teórico-metodológicas, Madrid, Tecnos, pp. 13-52 (reproducido en Revista Latina de Comunicación Social, 64, 1-14, 2009).

MARTIINEZ NICOLÁS, M. (2014): "La investigación española sobre Comunicación de mayor visibilidad internacional. Análisis de los trabajos publicados en las revistas internacionales del Journal Citation Reports (JCR) y el SCImago Journal \& Country Rank (SJR-Scopus)". Ponencia presentada en el IV Congreso Internacional de la Asociación Española de Investigación de la Comunicación (Bilbao).

MARTÍNEZ NICOLÁS, M. y SAPERAS, E. (2011): "La investigación sobre Comunicación en España (1998-2007). Análisis de los artículos publicados en revistas científicas", Revista Latina de Comunicación Social, 66, pp. 101-129.

MARTÍNEZ NICOLÁS, M. y SAPERAS, E. (2016): “Objetos de estudio y orientación metodológica de la reciente investigación sobre comunicación en España (20082014). Análisis de los trabajos publicados en revistas científicas españolas", Revista Latina de Comunicación Social, 71, pp. 1365-1384.

MARTÍNEZ NICOLÁS, M.; SAPERAS, E. y CARRASCO-CAMPOS, Á. (2017): "La investigación sobre periodismo en España. Análisis de los trabajos publicados en revistas científicas españolas en los últimos 25 años (1990-2014)", Communication \& Society, 30 (4), pp. 149-166.

MARTÍNEZ PASTOR, E. y GARCÍA LÓPEZ, J. (2013): "Investigación sobre publicidad digital en las revistas científicas españolas", El Profesional de la Información, 22 (2), pp. 173-180.

MARTÍNEZ PESTAÑA, M. J. (2011): «La investigación universitaria en Publicidad: producción y temática de las tesis doctorales (1971-2001), Documentación de las Ciencias de la Información, 34, pp. 119-156.

MASIP, P. (2011): "Los efectos del efecto ANECA: análisis de la producción española en comunicación en el Social Sciences Citation Index (1999-2009)", en J. L. Piñuel, C. Lozano y A. García Jiménez (eds.), Investigar la comunicación en España, Madrid, Asociación Española de Investigación de la Comunicación, pp. 649-663.

MÍGUEZ, M. I.; BAAMONDE, X. M. y CORBACHO, J. M. (2014): “A bibliographic study of public relations in Spanish media and communication journals, 2000-2012", Public Relations Review, 40 (5), pp. 818-828.

MORAGAS, M. de (1981): Teorías de la comunicación. Investigaciones sobre medios en América y Europa, Barcelona, Gustavo Gili.

MORAGAS, M. de (2005): "Investigación de la comunicación y política científica en España". Ponencia presentada en la Reunión Científica de la Sociedad Española de Periodística (Santiago de Compostela).

PIÑEIRO, T. (2016): "La radio en la investigación comunicativa en España: una línea minoritaria para un medio mayoritario", Signo y Pensamiento, 69, pp. 30-48. 
REPISO, R.; TORRES, D. y DELGADO, E. (2011a): “Análisis de la investigación sobre Radio en España: una aproximación a través del análisis bibliométrico y de redes sociales de las tesis doctorales defendidas en España entre 1976-2008”, Estudios sobre el Mensaje Periodístico, 17 (2), pp. 417-429.

REPISO, R.; TORRES, D. y DELGADO, E. (2011b): “Análisis bibliométrico y de redes sociales en tesis doctorales españolas sobre televisión (1976/2007)", Comunicar. Revista Científica de Comunicación y Educación, 37, pp. 151-159.

ROCA, D. y MENSA, M. (2009): «Las metodologías utilizadas en las investigaciones de creatividad publicitaria (1965-2007)», Comunicación y Sociedad, 22 (2), pp. 7-34.

RODRIGO, M. y GARCÍA JIMÉNEZ, L. (2010): "Communication theory and research in Spain: A paradigmatic case of a socio-humanistic discipline", European Journal of Communication, 25 (3), pp. 273-286.

SAPERAS, E. (2016): "Cuatro décadas de investigación comunicativa en España. Los procesos de institucionalización y profesionalización de la investigación”, Disertaciones. Anuario Electrónico de Estudios en Comunicación Social, 9 (2), pp. 27-45.

SILVA, V. y SAN EUGENIO, J. (2014): "La investigación en Comunicación ante una encrucijada: de la teoría de los campos a la diseminación y diversidad gnoseológica. Estudio inicial comparado entre España, Brasil y Chile", Palabra Clave, 17 (3), pp. 803-827.

SORIANO, J. (2008): "El efecto ANECA". Comunicación presentada en el I Congreso de la Asociación Española de Investigación de la Comunicación (Santiago de Compostela).

SORIANO, J. (2017): "La política estatal de recompenses als investigadors en comunicació: breu anàlisi crítica", Comunicació. Revista de Recerca i d'Anàlisi, 34 (2), pp. 33-51.

VASSALLO DE LOPES, M. I. (1990): Pesquisa em comunicação. Formulação de um modelo metodológico, São Paulo, Edições Loyola. 
